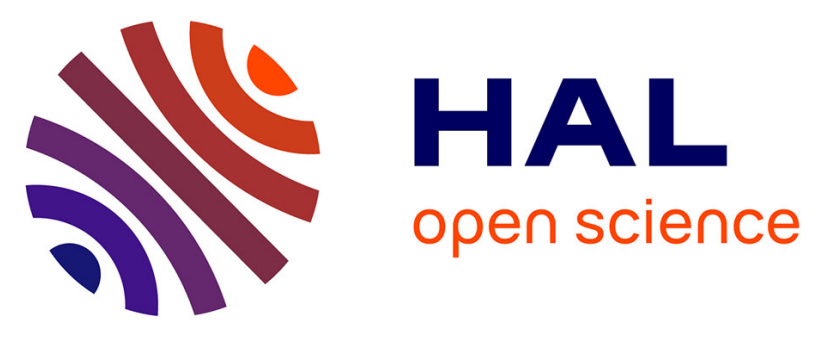

\title{
AMMA Land Surface Model Intercomparison Experiment coupled to the Community Microwave Emission Model: ALMIP-MEM
}

Patricia de Rosnay, M. Drusch, A. Boone, G. Balsamo, B. Decharme, P. Harris, Yann H. Kerr, Thierry Pellarin, J. Polcher, J.-P. Wigneron

\section{To cite this version:}

Patricia de Rosnay, M. Drusch, A. Boone, G. Balsamo, B. Decharme, et al.. AMMA Land Surface Model Intercomparison Experiment coupled to the Community Microwave Emission Model: ALMIP-MEM. Journal of Geophysical Research: Atmospheres, 2009, 114 (D05108), pp.D05108. 10.1029/2008JD010724 . insu-00413399

\section{HAL Id: insu-00413399 \\ https://hal-insu.archives-ouvertes.fr/insu-00413399}

Submitted on 5 Mar 2021

HAL is a multi-disciplinary open access archive for the deposit and dissemination of scientific research documents, whether they are published or not. The documents may come from teaching and research institutions in France or abroad, or from public or private research centers.
L'archive ouverte pluridisciplinaire HAL, est destinée au dépôt et à la diffusion de documents scientifiques de niveau recherche, publiés ou non, émanant des établissements d'enseignement et de recherche français ou étrangers, des laboratoires publics ou privés. 


\title{
AMMA Land Surface Model Intercomparison Experiment coupled to the Community Microwave Emission Model: ALMIP-MEM
}

\author{
P. de Rosnay, ${ }^{1}$ M. Drusch, ${ }^{1}$ A. Boone,${ }^{2}$ G. Balsamo, ${ }^{1}$ B. Decharme, ${ }^{2}$ P. Harris,${ }^{3}$ Y. Kerr, ${ }^{4}$ \\ T. Pellarin, ${ }^{5}$ J. Polcher, ${ }^{6}$ and J.-P. Wigneron ${ }^{7}$ \\ Received 4 July 2008; revised 4 December 2008; accepted 8 January 2009; published 11 March 2009.
}

[1] This paper presents the African Monsoon Multidisciplinary Analysis (AMMA) Land Surface Models Intercomparison Project (ALMIP) for Microwave Emission Models (ALMIP-MEM). ALMIP-MEM comprises an ensemble of simulations of C-band brightness temperatures over West Africa for 2006. Simulations have been performed for an incidence angle of $55^{\circ}$, and results are evaluated against C-band satellite data from the Advanced Microwave Scanning Radiometer on Earth Observing System (AMSR-E). The ensemble encompasses 96 simulations, for 8 Land Surface Models (LSMs) coupled to 12 configurations of the Community Microwave Emission Model (CMEM). CMEM has a modular structure which permits combination of several parameterizations with different vegetation opacity and soil dielectric models. ALMIP-MEM provides the first intercomparison of state-of-theart land surface and microwave emission models at regional scale. Quantitative estimates of the relative importance of land surface modeling and radiative transfer modeling for the monitoring of low-frequency passive microwave emission on land surfaces are obtained. This is of high interest for the various users of coupled land surface microwave emission models. Results show that both LSMs and microwave model components strongly influence the simulated top of atmosphere (TOA) brightness temperatures. For most of the LSMs, the Kirdyashev opacity model is the most suitable to simulate TOA brightness temperature in best agreement with the AMSR-E data. When this best microwave modeling configuration is used, all the LSMs are able to reproduce the main temporal and spatial variability of measured brightness temperature. Averaged among the LSMs, correlation is 0.67 and averaged normalized standard deviation is 0.98 .

Citation: de Rosnay, P., M. Drusch, A. Boone, G. Balsamo, B. Decharme, P. Harris, Y. Kerr, T. Pellarin, J. Polcher, and J.-P. Wigneron (2009), AMMA Land Surface Model Intercomparison Experiment coupled to the Community Microwave Emission Model: ALMIP-MEM, J. Geophys. Res., 114, D05108, doi:10.1029/2008JD010724.

\section{Introduction}

[2] Soil moisture is a crucial variable of the Earth system. It controls the partitioning of energy in latent and sensible heat fluxes that occurs at the soil-atmosphere interface and it is a major variable of the continental hydrological cycle [Dirmeyer et al., 1999; Entekhabi et al., 1999; Milly and Dunne, 1994]. Soil moisture strongly influences the seasonal and interannual dynamics of the vegetation which is an essential component of the coupled hydrological and carbon cycles [Calvet et al., 2008; Ciais et al., 2005; Foley et al.,

\footnotetext{
${ }^{1}$ European Centre for Medium-Range Weather Forecasts, Reading, UK.

${ }^{2}$ CNRM, Météo-France, Toulouse, France.

${ }^{3}$ Centre for Ecology and Hydrology, Wallingford, UK.

${ }^{4}$ Centre d'Etudes Spatiales de la Biosphère, Toulouse, France.

${ }^{5}$ Laboratoire d'étude des Transferts en Hydrologie et Environnement, Grenoble, France.

${ }^{6}$ Laboratoire de Météorologie Dynamic, IPSL, Paris, France.

${ }^{7}$ Ecologie Fonctionnelle et Physique de l'environnement, INRA Centre Bordeaux-Aquitaine, Villenave d'Ornon, France.
}

Copyright 2009 by the American Geophysical Union. 0148-0227/09/2008JD010724
1996; Nepstad et al., 1994]. Soil moisture is a main variable for specifying the lower boundary condition of the atmosphere. Accurate estimation of initial state soil moisture conditions is thus important for numerical weather and climate predictions. Koster et al. [2004] showed that precipitation is somewhat affected by soil moisture conditions and they identified three hot spot regions where feedback mechanisms between soil moisture and precipitation are strongest, in the Great Plains of North America, the Sahel, and India. Over Sahel, Taylor et al. [2007] and Taylor [2008] pointed out that soil moisture and land surface processes highly influence the dynamics of the mesoscale convective systems.

[3] Coordinated land surface modeling activities have improved our understanding of land surface processes. The Project for the Intercomparison of Land Surface Parameterization Schemes (PIPLS) [Lettenmaier, 2003; HendersonSellers et al., 1995] has provided local-scale off-line (i.e., decoupled from an atmospheric model) intercomparisons of Land Surface Models (LSMs) for more than a decade. Within the wider context of Global Energy and Water Experiment (GEWEX), PILPS is part of the Global Land Atmosphere System Study (GLASS). The Global Soil Wetness Project-2 
(GSWP-2) provided global estimates of soil moisture and land surface fluxes [Dirmeyer et al., 2006]. GSWP-2 simulations were performed globally with a $1^{\circ} \times 1^{\circ}$ grid, using the International Satellite Land Surface Climatology Project (ISLSCP) Initiative II data set for 1986-1995 [Hall et al., 2001]. The AMMA (African Monsoon Multidisciplinary Analysis) Land Surface Model Intercomparison Project (A. Boone et al., The AMMA Land Surface Model Intercomparison Project (ALMIP), submitted to Bulletin of the American Meteorological Society, 2009) is being conducted for $2002-2006$, at a $0.5^{\circ} \times 0.5^{\circ}$ grid. Within the AMMA project [Redelsperger et al., 2006], one of the key objective of ALMIP is to get a better understanding of the role of soil moisture in land surface processes in West Africa. For 20042006, ALMIP simulations are of particular interest since they use a forcing data set which combines model fields and satellite data for precipitation and radiative fluxes (Boone et al., submitted manuscript, 2009).

[4] In this paper, results of the ALMIP-MEM (Microwave Emission Model) project are presented. ALMIP-MEM aims at coupling the ALMIP soil moisture and soil temperature outputs provided by an ensemble of LSMs for the year 2006, to the Community Microwave Emission Model [Drusch et al., 2009; Holmes et al., 2008] to simulate C-band (6.9 GHz) brightness temperatures as seen by the Advanced Microwave Scanning Radiometer on Earth Observing System (AMSR-E) lowest-frequency channel. AMSR-E brightness temperature data are used to provide an integrated evaluation of the coupled ALMIP-MEM approach. The CMEM forward model has been developed by the European Centre for MediumRange Weather Forecasts (ECMWF) to simulate top of atmosphere (TOA) low-frequency (1.4 GHz to $20 \mathrm{GHz}$ ) passive microwave emission. CMEM considers different dielectric layers (soil, vegetation, atmosphere) contributing to the TOA brightness temperature. Microwave emission models for these different components have been individually developed, calibrated and validated at local scale on the basis of different field experiments for different soil, vegetation and climate conditions. Some of them have been used at the field scale, on the basis of aircraft measurements [Wigneron et al., 2007; de Rosnay et al., 2006; Jackson et al., 1999; Wigneron et al., 1996; Schmugge, 1992; Jackson and Schmugge, 1991; Jackson and O'Neill, 1990; Wang and Schmugge, 1980]. Gao et al. [2004] used the L-MEB model [Pellarin et al., 2003 ] to simulate a 10-year time series of synthetic L-band (1.4 GHz) temperature from the GSWP-2 output of four LSMs. They used aircraft measurements acquired during the GSWP-2 period to evaluate the coupled approach. All these studies contributed to improve our understanding of the microwave emission over land surfaces. They were the basis for the development of the current microwave emission models.

[5] Emission models are a key component of the satellite data inversion and data assimilation systems. The future SMOS (Soil Moisture and Ocean Salinity) [Kerr et al., 2001] is a European Space Agency (ESA) Earth Explorer demonstration satellite mission. It is expected to be launched in 2009 and will be followed by the NASA SMAP (Soil Moisture Active and Passive) mission in 2013. SMOS will be the first satellite devoted to soil moisture remote sensing over land. For NWP (Numerical Weather Prediction), assimilation of SMOS data is envisaged and several meteorological centers are currently developing Extended Kalman Filter techniques for soil moisture analysis [Mahfouf et al., 2009; M. Drusch et al., Towards a Kalman filter based soil moisture analysis system for the operational ECMWF Integrated Forecast System, submitted to Geophysical Research Letters, 2009]. SMOS data will be used for many applications, including NWP, hydrology, and climate modeling, by several groups with different land surface and different forward emission models.

[6] The present work represents the first coordinated microwave emission models regional intercomparison experiment. ALMIP-MEM takes advantage of the experience of the land surface modeling community in intercomparison studies. ALMIP-MEM combines 8 LSMs with 12 microwave emission model configurations of CMEM. In total 96 ALMIP-MEM brightness temperatures simulations were performed for each ALMIP experiment. They are evaluated against AMSR-E C-band data for the year 2006 over the West African Region. In contrast to the previous studies above mentioned, the purpose of this study is not to calibrate again the microwave emission models to obtain the best fit with AMSR-E data over the particular studied region. Rather, this study aims at investigating the relative importance of Microwave Emission Models and Land Surface Models on the accuracy of simulated brightness temperatures, when compared to the AMSR-E C-band brightness temperatures. For the future SMOS and SMAP users, as well as for the space agencies, it is of high interest to quantify the relative importance of the different elements of the modeling system, including land surface and microwave components. For NWP, it is crucial to identify the best microwave modeling approach to be used for low-frequency brightness temperature data assimilation and soil moisture analysis.

[7] Section 2 presents the data and method. This includes AMSR-E data, the Community Microwave Emission Model, the AMMA Land Surface Model Intercomparison Project, the ALMIP-MEM experiments and the method for comparing AMSR-E data and ALMIP-MEM outputs. Section 3 presents the ALMIP-MEM results and section 4 provides summary and conclusions.

\section{Data and Method}

\subsection{AMSR-E Satellite Data}

[8] AMSR-E on the NASA's AQUA satellite was launched in 2002. AMSR-E instruments operate in polar Sun-synchronous orbits, with equator crossings at 0130 local time (LT) (descending orbit) and 1330 LT (ascending orbit), measuring microwave brightness temperatures at five frequencies with an incidence angle of $55^{\circ}$. C-band and X-band channels (6.9 and $10.7 \mathrm{GHz}$ ) are suitable for soil moisture monitoring [Njoku et al., 2003]. At C-band brightness temperature is sensitive to the very top $(\sim 2 \mathrm{~cm})$ soil moisture, vegetation water content and effective temperature. AMSR-E products include measured brightness temperature. They are archived and distributed routinely by NASA National Snow and Ice Data Center (NSIDC) Distributed Active Archive Center (DAAC) on a global cylindrical 25-km Equal-Area Scalable Earth Grid (EASE-Grid) cell spacing [Njoku, 2004].

[9] Possible Radio Frequency Interference (RFI) is observed in the $6.9 \mathrm{GHz}$ and $10.7 \mathrm{GHz}$ (X-band) channels [Njoku et al., 2005; Li et al., 2004]. RFI contamination is observed in Japan, Europe, the Middle East, and southern Africa and 
North America. In other areas, the accuracy of the measured brightness temperature is better than $1 \mathrm{~K}$. Sun-glint effects, which are not due to instrument errors, might also affect the signal of the ascending orbit.

[10] In this study C-band brightness temperatures of AMSR-E are used over West Africa and for the descending orbit. They are not affected by RFI nor Sun-glint effects.

\subsection{Soil Moisture Ground Data}

[11] In the framework of the AMMA Enhanced Observing Period [Redelsperger et al., 2006] West Africa has been extensively instrumented. In particular, the Agoufou site located in Mali at $15.3^{\circ} \mathrm{N}, 1.5^{\circ} \mathrm{W}$ includes a soil moisture measurement network that will be used for the future validation of SMOS. The soil moisture scaling properties have been investigated by de Rosnay et al. [2009] from which a relationship has been determined to derive kilometric-scale soil moisture from the most representative station of the network. The Agoufou soil moisture data set has also been used to evaluate AMSR-E soil moisture products by Gruhier et al. [2008]. This data set is used in this study to illustrate at local scale the consistency between ground measurements of surface $(5 \mathrm{~cm})$ soil moisture and soil temperature and brightness temperatures (observed and simulated).

\subsection{Community Microwave Emission Model}

[12] The Community Microwave Emission Model (CMEM) is the observation operator developed by the ECMWF to simulate low-frequency passive microwave brightness temperatures (from $1 \mathrm{GHz}$ to $20 \mathrm{GHz}$ ) of the surface [Drusch et al., 2009; Holmes et al., 2008]; http:/www.ecmwf.int/research/ ESA_projects/SMOS $/ \mathrm{cmem} / \mathrm{cmem}$ index.html. The TOA brightness temperature results from the contribution of three dielectric layers (soil, vegetation, atmosphere). It is expressed at polarization $p$,

$$
\begin{gathered}
T_{\text {Btoa, }, p}=T_{\text {Bau }, p}+\exp ^{-\tau_{\text {atm }, p}} \cdot T_{\text {Btov }, p} \\
T_{\text {Btov }, p}=T_{\text {Bsoil }, p} \cdot e^{-\tau_{\text {veg }, p}}+T_{\text {Bveg }, p}\left(1+r_{r, p} e^{-\tau_{\text {veg }, p}}\right) \\
+T_{\text {Bad }, p} \cdot r_{r, p} \cdot e^{-2 \cdot \tau_{\text {veg }, p}} .
\end{gathered}
$$

$T_{\text {Btov, } p}(\mathrm{~K})$ is the top of vegetation brightness temperature. In this formulation vegetation is represented as a homogeneous layer with an optical depth $\tau_{v e g, p}$ along the viewing path, with a brightness temperature $T_{B v e g, p}(\mathrm{~K}) . T_{B a u, p}(\mathrm{~K})$ and $T_{B a d, p}(\mathrm{~K})$ are brightness temperatures resulting from upward and downward radiations; $\tau_{\text {atm, }}$ is the atmospheric optical depth. $T_{\text {Bsoil,p }}(\mathrm{K})$ is the soil brightness temperatures and $r_{r, p}$ is the soil reflectivity of the rough surface. In equation (2), the soil brightness temperature is expressed according to the Rayleigh-Jeans approximation for the microwave domain as the product of the soil emissivity $e_{r, p}$ and the effective temperature,

$$
T_{B s o i l, p}=T_{e f f} \cdot e_{r, p}
$$

On the basis of equations (1), (2), and (3), CMEM includes a modular choice of the physical parameterizations for the soil,

\begin{tabular}{|c|c|c|c|}
\hline \multirow[b]{2}{*}{ Vegetation Optical Depth } & \multicolumn{3}{|c|}{ Dielectric Constant } \\
\hline & $\begin{array}{c}\text { Dobson et al. } \\
\text { [1985] }\end{array}$ & $\begin{array}{c}\text { Mironov et al. } \\
{[2004]}\end{array}$ & $\begin{array}{c}\text { Wang and } \\
\text { Schmugge } \\
{[1980]}\end{array}$ \\
\hline Jackson and O'Neill [1990] & 1 & 5 & 9 \\
\hline Kirdyashev et al. [1979] & 2 & 6 & 10 \\
\hline Wegmüller et al. [1995] & 3 & 7 & 11 \\
\hline Wigneron et al. [2007] & 4 & 8 & 12 \\
\hline
\end{tabular}
vegetation and atmosphere dielectric layers, such as those
Table 1. Physical Parameterizations Used in CMEM for ALMIP-MEM $^{\mathrm{a}}$

${ }^{\mathrm{a}}$ Twelve configurations are considered for different combinations of soil dielectric and vegetation optical depth models.

used in the L-Band Microwave Emission of the Biosphere (L-MEB) [Wigneron et al., 2007] and Land Surface Microwave Emission Model (LSMEM) [Drusch et al., 2001]. For the soil, as described by Drusch et al. [2009], three parameterizations are considered for the dielectric constant, four for the effective temperature, two for the smooth emissivity model and five for the soil roughness. The vegetation optical depth can be represented by a choice of four different parameterizations and the atmospheric opacity by three parameterizations. Consequently, CMEM provides a total of 1440 different combinations. This study does not test all these possible configurations. The soil effective temperature and the atmospheric opacity models of Choudhury et al. [1982] and Pellarin et al. [2003] are chosen. The smooth emissivity is represented with the Fresnel Law and the effects of soil roughness are parameterized using the Choudhury et al. [1979] parameterization.

[13] The sensitivity of the simulated brightness temperature is investigated for different configurations of the vegetation optical depth and the soil dielectric constant. These two components of the microwave emission model are strongly related to soil moisture and vegetation water content which are the main contributors affecting the sensitivity of the TOA brightness temperature, as shown by Jones et al. [2004]. Soil water content and vegetation water content have opposite effects on the microwave emission. When vegetation water content increases the scatter and absorption increases and the emission is more important. In contrast, when the soil is getting wet, the soil dielectric constant increases and the emission is reduced.

[14] Table 1 summarizes the microwave modeling parameterizations used in this study concerning vegetation opacity and dielectric models. It indicates the 12 configurations of vegetation opacity and dielectric models and gives an index number for each, which will be used in the following. A short description of the soil dielectric constant and vegetation opacity models used in this study is provided hereafter. More detailed descriptions of all parameterizations used in CMEM can be found in the references listed in Table 1 and given by Drusch et al. [2009].

\subsubsection{Soil Dielectric Models}

[15] Microwave remote sensing of soil moisture relies on the large contrast between the dielectric constant of water $(\sim 80)$ and that of dry soils $(\sim 4)$. The soil dielectric mixing model relates the soil dielectric constant to the volumetric soil moisture and soil texture, frequency of detection and surface soil temperature. Several dielectric models have been proposed in the literature. The Wang and Schmugge [1980] and 
Table 2. CMEM Vegetation Parameters for the Four Considered Parameterizations

\begin{tabular}{|c|c|c|c|c|c|c|}
\hline \multirow[b]{2}{*}{ Parameterizations } & \multirow[b]{2}{*}{ Parameter } & \multicolumn{2}{|c|}{ Low Vegetation Types } & \multicolumn{3}{|c|}{ High Vegetation Types (Forest) } \\
\hline & & Crops & Grass & Rain & Deciduous & Coniferous \\
\hline Jackson and O'Neill [1990] & $\omega$ & 0.05 & 0.05 & 0.05 & 0.05 & 0.05 \\
\hline Kirdyashev et al. [1979] and Wegmüller et al. [1995] & VWC & 0.5.LAI & $0.5 . \mathrm{LAI}$ & 10 & 4 & 3 \\
\hline Kirdyashev et al. [1979] and Wegmüller et al. [1995] & ageo & 0.33 & 0.33 & 0.66 & 0.66 & 0.66 \\
\hline Jackson and O'Neill [1990] & $\mathrm{b}$ & 0.2 & 0.15 & 0.33 & 0.33 & 0.33 \\
\hline \multirow[t]{5}{*}{ Wigneron et al. [2007] } & $\mathrm{b}^{\prime}$ & 0.2 & 0.2 & 0 & 0 & 0 \\
\hline & $b^{\prime \prime}$ & 0 & 0.00 & 0.7 & 0.69 & 0.7 \\
\hline & $\omega$ & 0.05 & 0.05 & 0.095 & 0.07 & 0.08 \\
\hline & tth & 1 & 1 & 1 & 0.49 & 0.8 \\
\hline & $\mathrm{ttv}$ & 1 & 1 & 1 & 0.46 & 0.8 \\
\hline
\end{tabular}

the Mironov et al. [2004] models consider the effect of bound water on the dielectric constant. They are limited to rather low frequencies in the range of about $1 \mathrm{GHz}$ to $10 \mathrm{GHz}$. The Dobson model is valid for a larger range of frequency $(1 \mathrm{GHz}$ to $18 \mathrm{GHz}$ ), but the dielectric constants computed from the Wang and Schmugge and the Mironov models are in better agreement with measurements for a large range of soil texture types [Vall-llossera et al., 2005; Mironov et al., 2004]. These three models are implemented in CMEM (Table 1).

\subsubsection{Vegetation Opacity Models}

[16] The emission of the vegetation is described in CMEM using the so-called $\tau-\omega$ approach in which the vegetation brightness temperature is expressed as a function of the canopy temperature $T_{c}$ corrected by an emissivity factor related to the extinction across the vegetation,

$$
T_{B v e g, p}=T_{c} \cdot\left(1-\omega_{p}\right) \cdot\left(1-e^{-\tau_{\text {veg, } p}}\right) .
$$

The extinction accounts for the vegetation optical depth $\tau_{v e g, p}$ and the single scattering albedo $\omega_{p}$ at polarization $p$. On the basis of the $\tau-\omega$ approach several parameterizations have been proposed to compute the vegetation optical thickness. The four approaches implemented in CMEM are indicated in Table 1. For each of them, the values of the parameters are indicated in Table 2 according to Holmes et al. [2008], Wigneron et al. [2007] and Pellarin et al. [2003].

[17] Jackson and Schmugge [1991] related the optical thickness to the vegetation water content (VWC) and an empirical parameter $b$ relating the vegetation structure,

$$
\tau_{\text {veg, }, p}=b \cdot \frac{V W C}{\cos \theta}
$$

The $b$ parameter is determined from field experiments for different vegetation types and the VWC is expressed as a linear function of the Leaf Area Index (LAI) [Pellarin et al., 2003]. In this parameterization the single scattering albedo is constant for low and high vegetation types.

[18] In the Wigneron et al. [2007] vegetation optical thickness model, the single scattering albedo depends on both vegetation type and polarization. The polarized optical thickness is expressed as

$$
\begin{gathered}
\tau_{\text {veg, }, p}=\tau_{\text {nadir }} \cdot\left(\cos ^{2} \theta+t t_{p} \sin ^{2} \theta\right) \frac{1}{\cos \theta} \\
\tau_{\text {nadir }}=b^{\prime} \cdot L A I+b^{\prime \prime},
\end{gathered}
$$

where $t t_{p}$ parameters represent the angular effect on vegetation optical thickness for each polarization and vegetation types. $\tau_{\text {nadir }}$ is the nadir optical depth and $b^{\prime}, b^{\prime \prime}$ are the vegetation structure parameters. Parameters used at C-band for this study for short vegetation types (crops and grass, Table 2) are based on work by Wigneron et al. [1995] and Pellarin et al. [2006].

[19] The Kirdyashev et al. [1979] parameterization is simple in terms of number of parameters, but it accounts for the observing frequency. It expresses the vegetation optical thickness as a function of the wave number $k$ (between $1 \mathrm{GHz}$ and $7.5 \mathrm{GHz}$ ), the dielectric constant of vegetation water, $\epsilon^{\prime \prime}{ }_{v w}$ (imaginary part), $V W C$, incidence angle $\theta$, water density $\rho_{\text {water }}$ and a vegetation structure parameter $a_{\text {geo }}$,

$$
\tau_{\text {veg, } p}=a_{\text {geo }} \cdot k \cdot \frac{V W C}{\rho_{\text {water }}} \cdot \epsilon_{v w}^{\prime \prime} \cdot \frac{1}{\cos \theta} .
$$

This parameterization has been used by Kerr and Njoku [1990] to investigate the multifrequency microwave signal over semiarid regions. It was extended to a larger range of frequencies $(1-100 \mathrm{GHz})$ by Wegmüller et al. [1995], by accounting for the wave number in the attenuation along the viewing path.

\subsubsection{Subgrid-Scale Variability}

[20] The brightness temperature at the top of the vegetation, $T_{B t o v, p}$, equation (2), can be computed for each model grid box taking the subgrid-scale variability of the land surface into account. Up to seven tiles can be considered in each CMEM grid box: bare soil, low vegetation, high vegetation (each are either free of snow or snow-covered) and open water. For low- and high-vegetation tiles, the dominant type is determined from the land cover data base. Within each grid cell, brightness temperatures are computed separately for each tile. The grid cell averaged brightness temperature is computed using a linear averaging of the brightness temperatures depending on the relative occurrence of each type of land cover.

\subsubsection{Forcing Variables and Parameters}

[21] To simulate TOA brightness temperatures CMEM requires (1) dynamic fields: the soil moisture and soil temperature profiles, 2-m air temperature, LAI, snow depth and snow density, and (2) static fields: soil texture, land cover, and geopotential at the surface which represents the surface elevation. More details concerning CMEM input/outputs are provided by Drusch et al. [2009]. For the ALMIP-MEM simulations performed in this study, the dynamic fields are obtained from the individual ALMIP simulations for each LSM. Soil texture, vegetation cover and LAI are important 
Table 3. Land Surface Models Used for ALMIP-MEM

\begin{tabular}{|c|c|c|c|}
\hline Name & Group & Soil Hydrology & Reference \\
\hline ISBA-FR & CNRM/Météo-France & Force Restore & Noilhan and Planton [1989] \\
\hline ISBA-DF & CNRM/Météo-France & Diffusion & Boone et al. [2000] \\
\hline HTESSEL & ECMWF & Diffusion & Balsamo et al. [2009] \\
\hline TESSEL & ECMWF & Diffusion & $\begin{array}{l}\text { van den Hurk et al. [2000] } \\
\text { Viterbo and Beljaars [1995] }\end{array}$ \\
\hline CTESSEL & ECMWF & Diffusion & Jarlan et al. [2007] \\
\hline JULES & MetOffice & Diffusion & $\begin{array}{l}\text { Blyth et al. }[2006] \\
\text { Essery et al. }[2003]\end{array}$ \\
\hline Noah & NCEP/EMC & Diffusion & $\begin{array}{l}\text { Chen and Dudhia [2001] } \\
\text { Decharme [2007] }\end{array}$ \\
\hline ORCHIDEE-CWRR & IPSL & Diffusion & $\begin{array}{l}\text { d'Orgeval et al. [2008], Krinner et al. [2005] } \\
\text { de Rosnay et al. }[2002]\end{array}$ \\
\hline
\end{tabular}

parameters which influence the simulated TOA brightness temperatures. Holmes et al. [2008] found a global sensitivity of $4 \mathrm{~K}$ in simulated brightness temperature to the vegetation map. For continental- to global-scale applications CMEM uses the ECOCLIMAP database for soil texture and land cover [Masson et al., 2003].

\subsection{AMMA Land Surface Models Intercomparison Project (ALMIP)}

[22] ALMIP is being conducted within the AMMA project Boone et al., submitted manuscript, 2009) http://www. cnrm.meteo.fr/amma-moana/amma_surf/almip/index.html). It intercompares results from several LSMs in order to determine which processes are missing or not adequately modeled by the current generation of LSMs over this region.

[23] LSMs require the following input forcing fields: precipitation, short-wave and long-wave radiative fluxes, wind speed (and direction), 2-m air humidity and temperature, surface pressure. The ALMIP forcing data are obtained from short-range ECMWF forecasts (FC) fields merged with the satellite based precipitation products obtained in EPSAT-SG (Estimation des Pluies par SATellite - Seconde Génération) [Chopin et al., 2004] and the OSI-SAF (OceanS and IceSatellite Application Facility) and Land-SAF radiative fluxes for 2004 and 2005-2006, respectively [Geiger et al., 2008; Boone et al., submitted manuscript, 2009].

[24] Forcing data for 2002-2003 have been used repetitively to spin up the LSMs. ALMIP simulations were performed at a $0.5^{\circ}$ resolution in latitude and longitude over the West African domain (from $5^{\circ} \mathrm{S}$ to $20^{\circ} \mathrm{N}$ in latitude and from $20^{\circ} \mathrm{W}$ to $30^{\circ} \mathrm{E}$ in longitude). Outputs have been provided from each LSM at a 3 hour time step for 2004-2006 Boone et al., submitted manuscript, 2009). They include, among other surface fields, soil moisture and soil temperature profiles, sensible and latent heat fluxes and runoff.

[25] In ALMIP-MEM 8 LSMs have been coupled to the CMEM forward operator (Table 3). Five of them are completely independent and three are derived versions of TESSEL and ISBA LSMs. Apart from ISBA-FR, which uses a force restore approach, all these LSMs use a physically based explicit representation of the soil hydrology by solving the Darcy equation extended to unsaturated soil. The thickness of the surface soil moisture layer is highly variable between the LSMs, ranging from millimeters (ORCHIDEE-CWRR and Noah) to $1 \mathrm{~cm}$ (ISBA-FR), $3 \mathrm{~cm}$ (ISBA-DF), $7 \mathrm{~cm}$ (HTESSEL, TESSEL, and CTESSEL) and $10 \mathrm{~cm}$ (JULES). For the coupling with CMEM, the top layer soil moisture is used, except for ORCHIDEE-CWRR and Noah which consider a very fine vertical discretization. For these two LSMs, soil moisture is aggregated over the first top four layers and top two layers, respectively, leading to a thickness of $2.15 \mathrm{~cm}$ for ORCHIDEE-CWRR and $2 \mathrm{~cm}$ to $10 \mathrm{~cm}$ for Noah which uses variable soil depths.

[26] HTESSEL (H stands for Hydrology) [Balsamo et al., 2009] is an improved version of TESSEL [van den Hurk et al., 2000; Viterbo and Beljaars, 1995]. HTESSEL is currently used operationally at ECMWF for NWP. It accounts for variable runoff infiltration as a function of soil texture and orography. CTESSEL (Carbon TESSEL) [Jarlan et al., 2007] results from the coupling between TESSEL and ISBA-A-gs [Calvet et al., 1998]. It describes the coupling between carbon and water cycles through a diagnostic computation of plant LAI and control of latent heat flux by the plants. ISBA-DF (diffusion scheme) is an option of ISBA [Noilhan and Planton, 1989] which accounts for multilayered explicit soil heat and water transfer [Boone et al., 2000]. JULES is the Met Office Surface Exchange Scheme (MOSES) [Essery et al., 2003], coupled to Top-down Representation of Interactive Foliage and Flora Including Dynamics (TRIFFID). It accounts for plant transpiration, soil evaporation, plant growth and soil respiration [Blyth et al., 2006]. Noah is used in the National Center for Environmental Prediction (NCEP) global Medium-Range Forecast model [Chen and Dudhia, 2001]. In this study, a recently improved version is used in which runoff is computed via a subgrid distribution of the topography using a new TOPMODEL approach [Decharme, 2007]. ORCHIDEE is the Institut Pierre-Simon Laplace land surface model [Krinner et al., 2005]. In the CWRR version used in this study, the soil water dynamics is physically based and the latent heat flux is controlled by the soil water and plant roots profiles [d'Orgeval et al., 2008; de Rosnay et al., 2002]. More detailed descriptions of these models can be found in the references given in Table 3.

\subsection{ALMIP-MEM Experiments}

[27] ALMIP-MEM considers the coupling between the 8 LSMs of Table 3 and the 12 microwave modeling configurations of Table 1. Combining these different LSMs and microwave models, ALMIP-MEM consists in one set of 96 simulations. Simulations are performed for the complete year 2006 in the AMSR-E configuration at $6.9 \mathrm{GHz}$ (C-band) and at $55^{\circ}$ incidence angle.

[28] ALMIP-MEM experiments are conducted without any calibration of the coupled LSMs-microwave emission 
models. Rather, we perform an intercomparison of different combinations of state-of-the-art LSMs and microwave emission models. We address the sensitivity of the TOA brightness temperatures, to the different components of the earth modeling system, including soil moisture and land surface modeling parameterizations as well as microwave emission parameterizations of vegetation and soil contributions.

\subsection{Statistical Comparison Between ALMIP-MEM and AMSR-E}

[29] In this study, C-band AMSR-E brightness temperature products are used to evaluate the ALMIP-MEM ensemble simulations over West Africa. To this end AMSR-E data are linearly interpolated to the ALMIP regular $0.5^{\circ}$ latitudelongitude grid and a temporal collocation is performed by using the time step of ALMIP-MEM outputs which is the nearest to the AMSR-E observing time. The results presented in this paper focus on horizontally polarized brightness temperature which is the most sensitive to the soil moisture and vegetation water content variability.

[30] To quantify each model's skill to simulate the observed brightness temperatures, we have computed for each modeling configuration the annual mean bias and three nondimensional statistics:

[31] 1. The correlation coefficient $(R)$ is computed for spatiotemporal fields and indicates whether the simulated and observed fields have similar spatiotemporal patterns.

[32] 2. The normalized standard deviation (SDV). It is the ratio of simulated $\sigma_{\text {sim }}$ by observed $\sigma_{o b s}$ standard deviations of brightness temperatures,

$$
\mathrm{SDV}=\sigma_{\text {sim }} / \sigma_{o b s}
$$

It gives the relative amplitude of the variations of the simulated field compared to those of the observed field.

[33] 3. The centered root mean square error between simulated and observed patterns is normalized by $\sigma_{o b s}$ the observed field standard deviation $(E)$. $E$ quantifies errors in the pattern of variations. Note that $E$ does not include any information on the overall biases since means of the fields are subtracted before computing second-order errors. It is expressed as

$$
E^{2}=\left(\mathrm{RMSE}^{2}-\mathrm{Bias}^{2}\right) / \sigma_{o b s}^{2}
$$

As shown by Taylor [2001], these three different statistics are complementary but not independent. They are related by

$$
E^{2}=\mathrm{SDV}^{2}+1-2 \cdot \mathrm{SDV} \cdot R
$$

On the basis of this relation, Taylor diagrams are generally used to represent on two-dimensional plots of these three different statistics [Taylor, 2001]. They display the normalized standard deviation (SDV) as a radial distance and the correlation with observations as an angle in the polar plot. Observed data are represented by a point located on the $x$ axis at $R=1$ and $\mathrm{SDV}=1$. The centered normalized $\mathrm{RMS}$ difference $(E)$ between the simulated and observed patterns, is the distance to this point.

[34] Statistics are computed on a West African subwindow which is delimited by $9^{\circ} \mathrm{N}-20^{\circ} \mathrm{N}$ and $10^{\circ} \mathrm{W}-10^{\circ} \mathrm{E}$. This window includes the north-south climatic gradient which characterizes the Sahelian area, but it excludes the coastal grid points and the southern area where C-band signal is expected to be constantly saturated by the tropical forest vegetation water content.

\section{Results}

\subsection{General Features of C-Band Brightness Temperature Over West Africa}

[35] Figure 1 illustrates an example of observed (AMSR-E) and simulated (ALMIP-MEM for ORCHIDEE in this example) brightness temperature (TB) at horizontal polarization on Days of Year (DOY) 200-201 and 220-221, for the descending orbit and in the CMEM configuration for which the dielectric constant is simulated with the Mironov model and the optical thickness with the Kirdyashev model.

[36] High values of soil moisture are characterized by low emission and thus low values of TB. In contrast, areas with high vegetation water content, as encountered at latitude between $4^{\circ} \mathrm{S}$ and $10^{\circ} \mathrm{N}$, have high brightness temperature values. Figure 1a clearly shows the presence of wet soil centered on $2^{\circ} \mathrm{W}, 15^{\circ} \mathrm{N}$ in the Sahelian region on DOY $200-$ 201 , with low values of TB. This typically corresponds to the occurrence of a monsoon season mesoscale convective rainfall event [Janicot et al., 2008]. This wet patch is very well reproduced by the ALMIP-MEM simulation (Figure 1a, right), with a spatial correlation $\mathrm{R}=0.66$. On DOY 220-221 (Figure 1b) the pattern is different indicating wet soil patches pattern has been evolving in space and time according to rainfall occurrence. The extend of the wet patches is slightly overestimated in the ALMIP-MEM simulation, but the correlation $(\mathrm{R}=0.71)$ indicates a good agreement between simulated and observed brightness temperatures.

[37] This result is extended to the whole annual cycle and for the eight ALMIP-MEM LSMs in Table 4 which shows statistics of the comparison between ALMIP-MEM and AMSR-E data. The microwave modeling configuration uses the Wang and Schmugge and Kirdyashev models (Table 1, configuration 10). This configuration provides the overall best performances in the microwave modeling approach for most LSMs as shown later.

[38] Land Surface Models that best represent the observations have highest correlation (R), lowest normalized root mean square error (E) and SDV value closest to one. Five LSMs show SDV values lower than 1, which indicate an underestimation of the amplitude of the variations compared to the observations. Two LSMs (TESSEL and CTESSEL) present SDV values higher than one, which indicate an overestimation of the signal amplitude. The overestimation of the SDV for these two models is related to their strong bias and it is due to the fact that they consider a uniform loamy textured soil instead of a coarse texture soil over Sahel. One LSM, HTESSEL, is able to reproduce the correct SDV, and two LSMs (Noah and ORCHIDEE-CWRR) show SDV in a $10 \%$ agreement with the observations. In term of bias, Table 4 shows that Noah, HTESSEL and ORCHIDEE-CWRR provide the best agreement with the AMSR-E data.

[39] A condensed quantitative view of the ALMIP-MEM results for the horizontal brightness temperature is provided by Figure 2, for CMEM configuration 10 (Table 1). This Taylor diagram quantifies the relative skill with which the different LSMs participating in ALMIP-MEM simulate the 

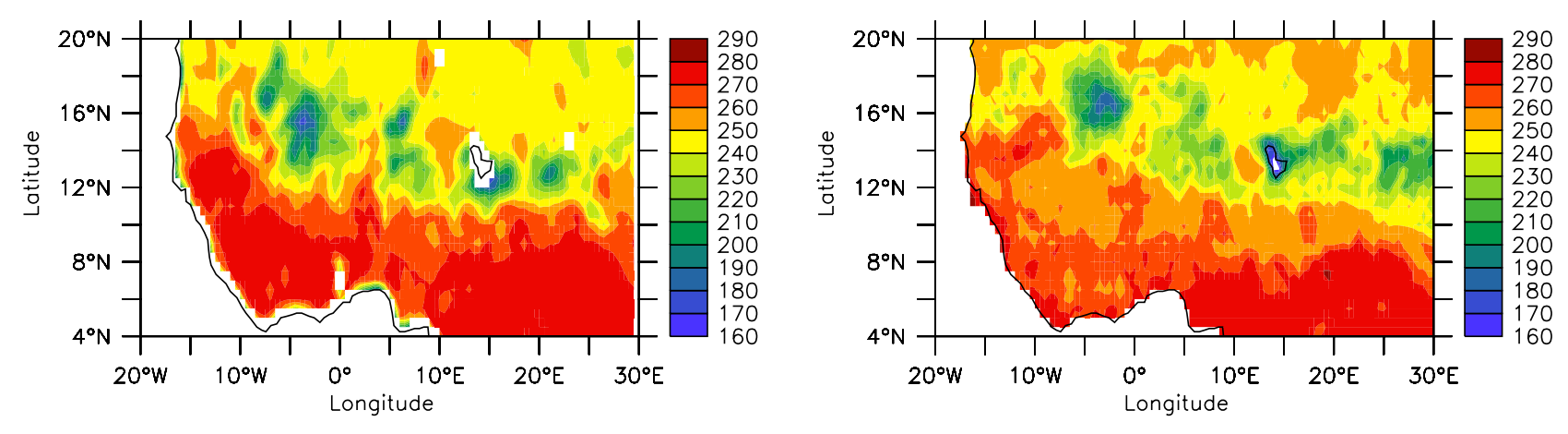

(a) Doy 200-201

ALMIP-MEM
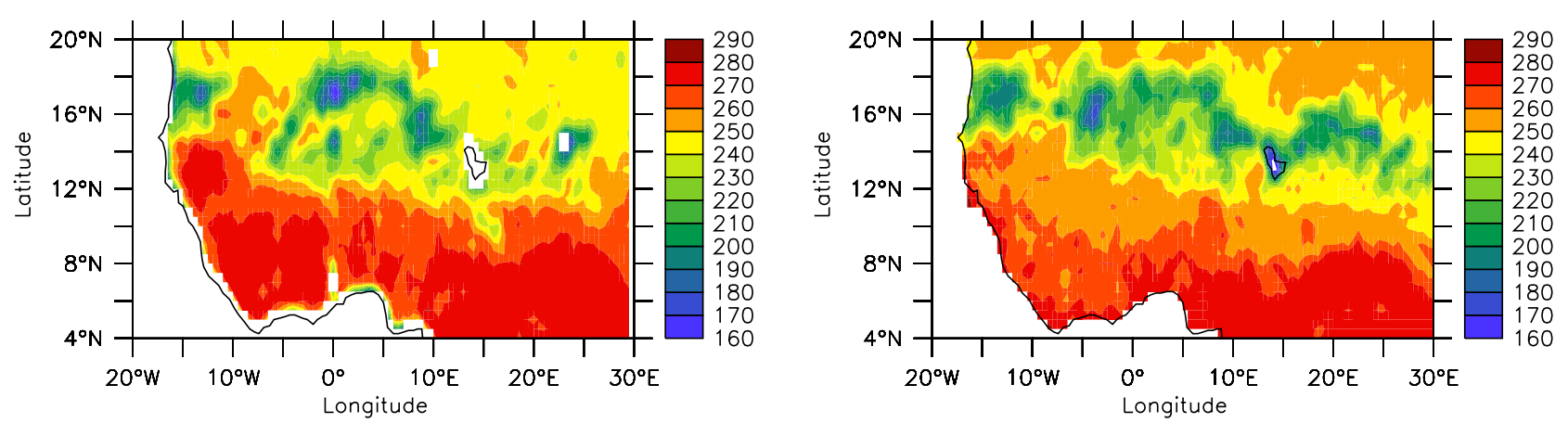

(b) Doy 220-221

ALMIP-MEM

Figure 1. C-band brightness temperature $(\mathrm{K})$ at horizontal polarization (left) observed by AMSR-E and (right) simulated by ALMIP-MEM for DOY (a) 200-201 and (b) 220-221. This example shows ORCHIDEE-CWRR results coupled to the Mironov dielectric model and the Kirdyashev opacity model (CMEM configuration 6 of Table 1).

spatial and temporal patterns of C-band brightness temperatures. Models lying on the dashed red arc have the correct standard deviation, which indicates that the amplitude of simulated variations are in agreement with that of observations.

[40] In agreement with statistics provided in Table 4, Figure 2 shows that the SDV is in the range of 0.67 to 1.36 and correlation values between modeled and observed brightness temperatures vary between 0.54 and 0.73 depending on the considered LSM. HTESSEL SDV is very close to one. It captures very well the amplitude of the spatiotemporal variations of $\mathrm{C}$-band brightness temperatures over West

Table 4. Statistics of the Comparison Between ALMIP-MEM Simulated and AMSR-E Observed C-band Brightness Temperatures at Horizontal Polarization for 2006 (Descending Orbit) ${ }^{\mathrm{a}}$

\begin{tabular}{lcccc}
\hline & $R$ & $E$ & SDV & Bias \\
\hline ISBA-FR & 0.69 & 0.74 & 0.86 & 4.5 \\
ISBA-DF & 0.73 & 0.68 & 0.71 & 5.2 \\
HTESSEL & 0.54 & 0.96 & 1.01 & 1.6 \\
TESSEL & 0.67 & 1.02 & 1.36 & -12.9 \\
CTESSEL & 0.69 & 0.98 & 1.36 & -13.5 \\
JULES & 0.63 & 0.78 & 0.67 & 10.9 \\
Noah & 0.72 & 0.72 & 0.90 & 1.1 \\
ORCHIDEE & 0.71 & 0.75 & 0.94 & 2.0 \\
& & & & \\
Average & 0.67 & 0.83 & 0.98 & -0.14 \\
\hline
\end{tabular}

${ }^{\mathrm{a}}$ These results are for the CMEM configuration 10 (Table 1). Best agreement between modeled and observed AMSR-E brightness temperatures are obtained for $R=1, \mathrm{SDV}=1, E=0$ and Bias $=0$ (section 2.6).
Africa for 2006. ISBA-DF has a low value of SDV, which indicates that it underestimates the amplitude of the variations. But it shows very good correlation and lowest RMS difference with the observations. When statistics are considered individually, model performances seem unrelated to the LSMs soil layer thickness. For example TESSEL and JULES both consider a relatively thick top soil layer $(7 \mathrm{~cm}$ and $10 \mathrm{~cm}$ ), but their performance to reproduce the observed SDV are drastically different (overestimates and underestimates, respectively). Some LSM perform well in terms of correlation with poor agreement with data in terms of SDV (ISBA-DF); others do a good job to reproduce SDV with poor correlation (HTESSEL).

[41] All the LSMs use the same atmospheric forcing and the same microwave emission model. Therefore, the scatter shown in Figure 2 results from differences in land surface processes parameterizations which lead to different simulated soil moisture and temperature. Many components of the LSMs influence the spatial and temporal structure of soil moisture, such as the vegetation seasonality, surface roughness and albedo, subgrid-scale representations of soil, vegetation and water bodies, routing and feedbacks between horizontal and vertical hydrology. However, it is clear from this Taylor diagram that the three LSMs that account for finest near surface soil moisture layers in the soil (ORCHIDEECWRR, Noah and ISBA-FR) provide overall best results when the three statistics are considered. This result is an indication that a fine top soil discretization is required to 


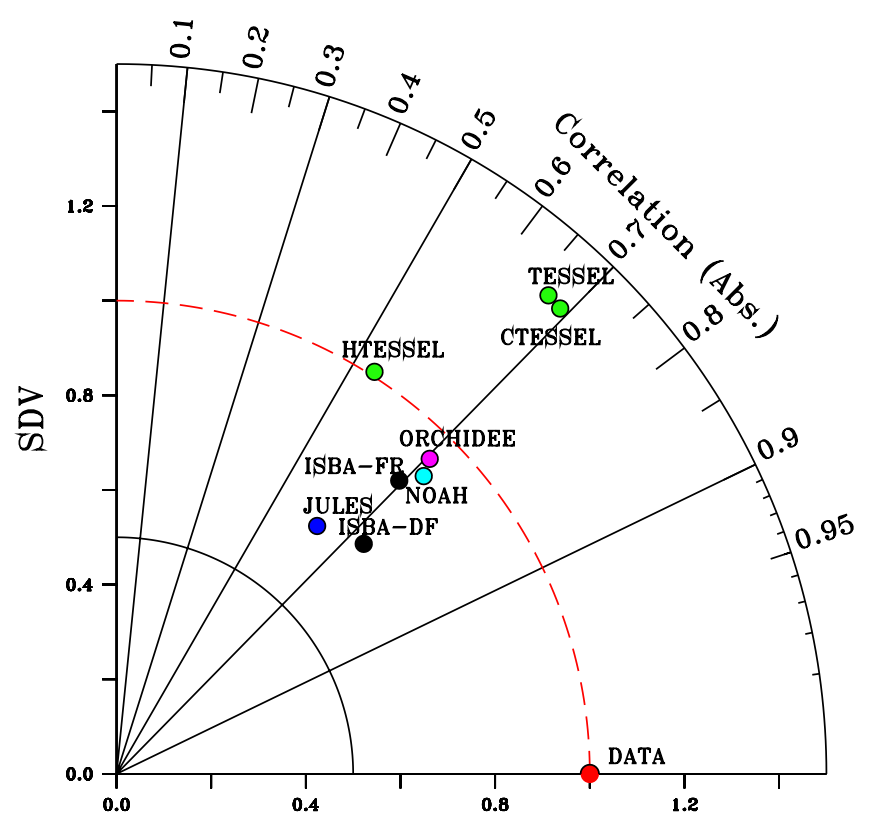

Figure 2. Taylor diagram illustrating the statistics of the comparison between ALMIP-MEM synthetic horizontal brightness temperature and AMSR-E data at C-band for different LSMs coupled to CMEM using the Wang and Schmugge dielectric model coupled to the Kirdyashev vegetation opacity model (CMEM configuration 10, Table 1). Each circle indicates for the considered LSM: the correlation value (angle), the normalized SDV (radial distance to the origin point), and the normalized centered root mean square error (distance to the point marked "Data"). One color is used for each LSM, according to Figures 4, 5, and 7.

simulate C-band microwave emission in good agreement with satellite data.

\subsection{Temporal Evolution of the Microwave Emission}

[42] Figure 3 shows the maps of the temporal correlation over the year 2006 between the AMSR-E data and the simulated TB at horizontal polarization, for the eight ALMIP-MEM LSMs for the studied window $\left(9^{\circ} \mathrm{N}-20^{\circ} \mathrm{N}\right.$ and $\left.10^{\circ} \mathrm{W}-10^{\circ} \mathrm{E}\right)$. For all the LSMs, simulated TB show contrasting results between the northern part of the window (Sahelian area) where correlation values indicate a good agreement with the observations, and the south of the window (Soudanian area) where correlation values are lower. The Sahel is characterized by a very marked annual cycle with a short monsoon season. For the very north, only a few precipitation events occur in the year. The resulting contrasted annual cycle is well reproduced by the models, leading to high values of correlation of simulated TB with AMSR-E data. In contrast the very south of the window has more constant annual cycle of TB, due to the constant presence of high vegetation types permitted by more important rainfall all along the year. This explains the low correlation values in the south between simulated and observed TB.

[43] To investigate further the latitudinal contrast in model performances shown in Figure 3, Figure 4 plots the mean temporal evolution of observed and simulated horizontal TB for two subwindows between $15^{\circ} \mathrm{N}$ and $20^{\circ}$ (north) and between $9^{\circ}$ and $15^{\circ} \mathrm{N}$ (south). For each model, brightness temperature is plotted after removal of the mean bias in each subwindow. This allows us to focus on the simulated signal variability, and this is suitable for future assimilation of brightness temperature for NWP for which a bias correction will be applied.
[44] The annual cycle is well reproduced by the simulations for all models. Over Sahel (north, Figure 4a, left), vegetation density and vegetation water content are rather limited. The surface emission is mainly controlled by the annual cycle of soil moisture and soil temperature. Maximum values of TB are reached before the monsoon season starts, around DOY 120-150 (May), which is the period of the year with highest soil temperatures and lowest soil moisture values. During the monsoon season, seasonal brightness temperature dynamics are controlled by both soil moisture and temperature with low effect of vegetation. At this time of the year, availability of soil moisture leads to high values of latent heat fluxes which decrease the surface temperature. Accordingly, the seasonal soil moisture increase and soil temperature decrease, both contribute to decrease TB values. At the end of the monsoon season, between DOY 240 and 280 (September-October) the occurrence of rainfall events is reduced and lower values of soil moisture are associated to lower latent heat fluxes and higher temperatures, both leading to increased TB values. Between DOY 300-365 and 1-150, the soil is very dry with low variability and brightness temperature variability is controlled by the soil temperature. It reaches a minimum in December-January when the winter of the northern hemisphere is associated with lower values of short-wave radiations.

[45] Over the southern window (Figure 4b, left), between $9^{\circ} \mathrm{N}$ and $15^{\circ} \mathrm{N}$, the monsoon onset occurs earlier in the year and the seasonal decrease of TB related to the monsoon, starts around DOY 120 (end of April). Vegetation cover is more important than in the northern part of the window and its impact on surface emission is larger. In particular persistent vegetation cover all the year along leads to a lower amplitude of the signal during the dry season. 


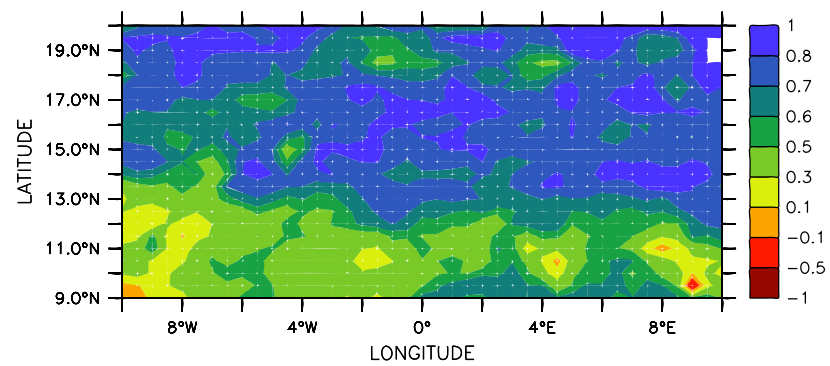

(a) ISBA-FR

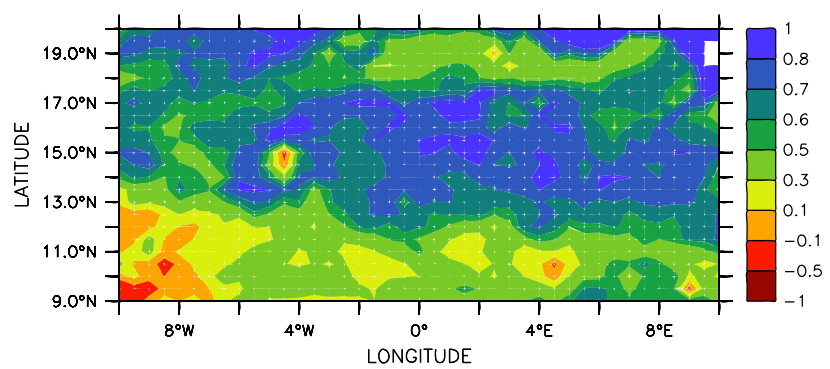

(c) HTESSEL

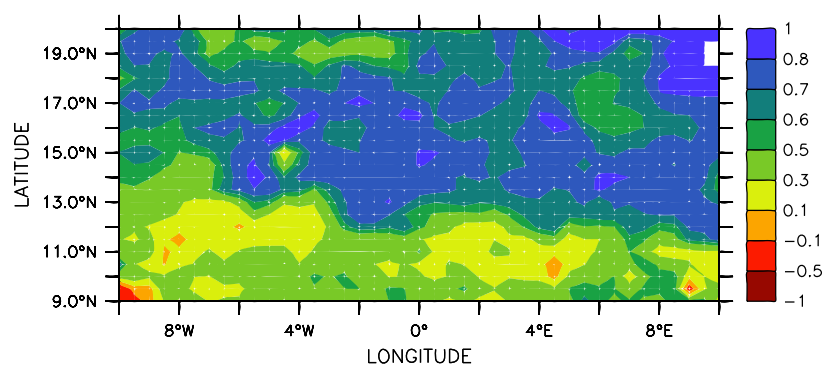

(e) CTESSEL

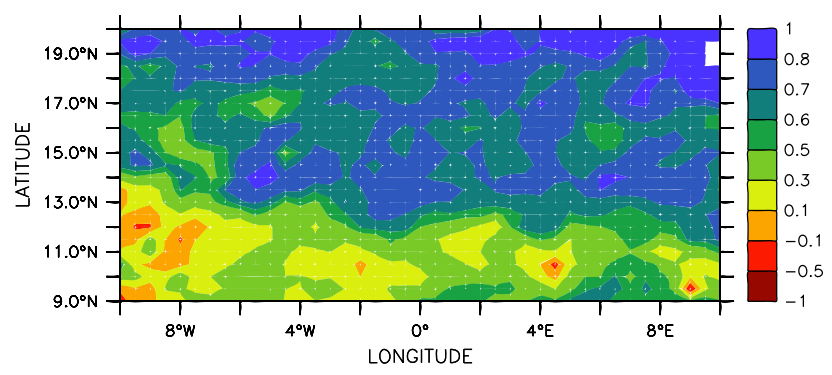

(g) $\mathrm{NOAH}$

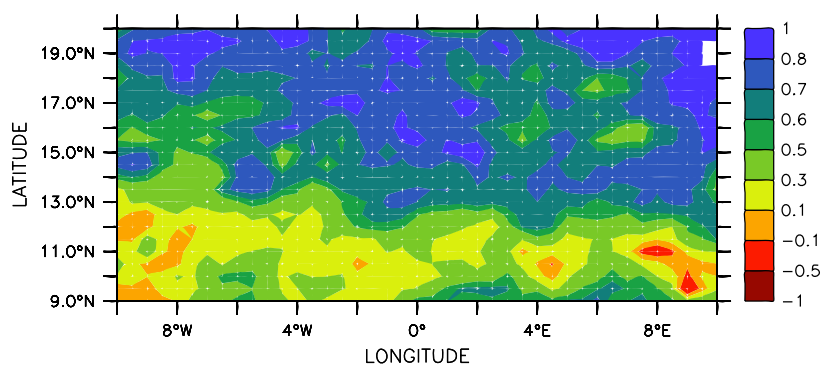

(b) ISBA-DF

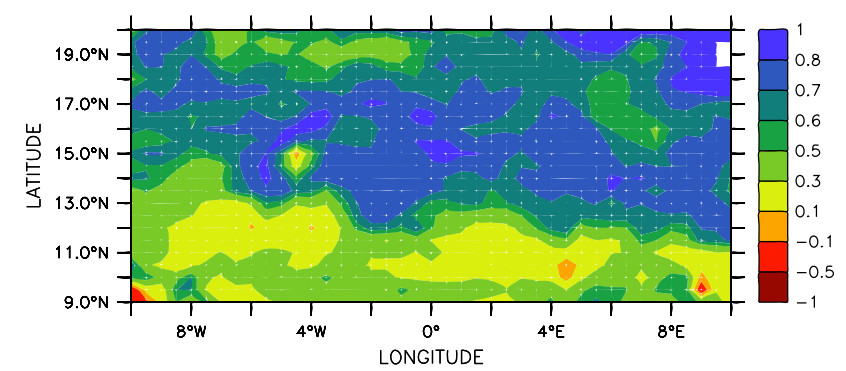

(d) TESSEL

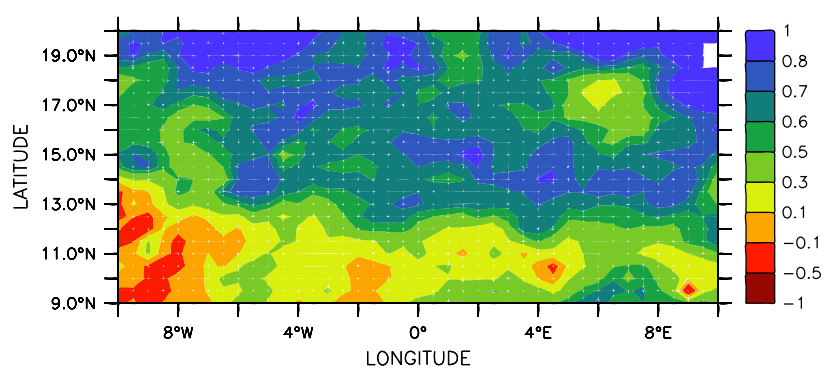

(f) JULES

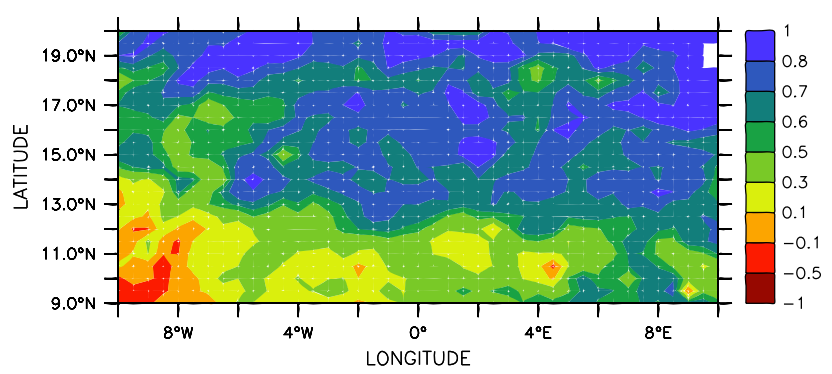

(h) ORCHIDEE-CWRR

Figure 3. Map of the temporal correlation between observed and simulated C-band horizontal brightness temperature for the eight ALMIP-MEM LSMs coupled to the Wang and Schmugge dielectric model and the Kirdyashev opacity model (CMEM configuration 6 of Table 1).

[46] At shorter temporal scale, at which precipitation events occur, the agreement between the models and AMSR-E data is still very good in terms of correlation, for the Sahelian area (Figure 4a, right). AMSR-E data show four minima of TB on DOY 201, 207, 216 and 218. All of them are associated with a decrease in simulated TB and the amplitudes are rather well captured for ISBA-FR, HTESSEL and ORCHIDEE-CWRR.

[47] On the southern part of the window (Figure 4b, right), where vegetation is denser, model performances at the precipitation event scale are clearly degraded as depicted in Figure 3. The amplitudes of the variations of brightness temperature are underestimated by all the LSMs. This is particularly the case on DOY 207 after a strong precipitation event occurred.

[48] Figure 5 shows the temporal evolution for DOY 229233 in August 2006 of simulated horizontal brightness temperature, soil temperature and soil moisture for the ALMIP-MEM grid point corresponding to the Agoufou super site in Sahel. This case study is limited to a few days but it illustrates the relationship between soil moisture and brightness temperature over Sahel for a typical convective rainfall event. The occurrence of a major rainfall event on 

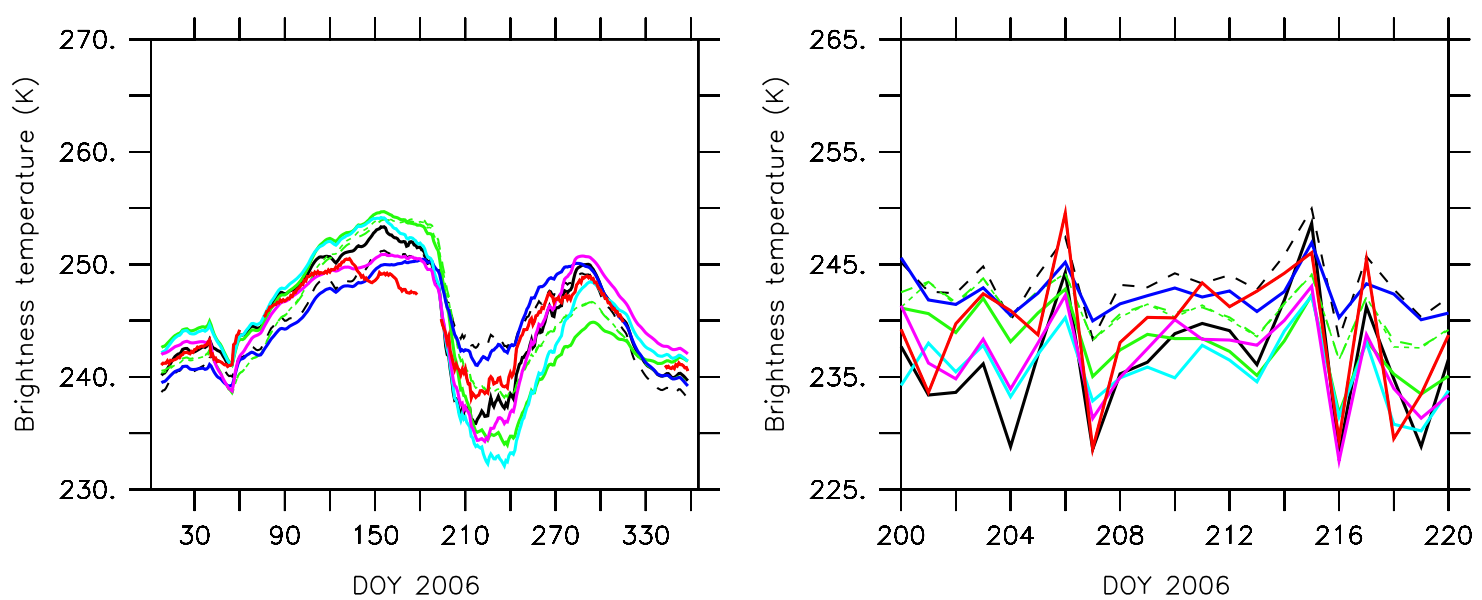

(a) North $\left(15-20^{\circ} \mathrm{N}\right)$
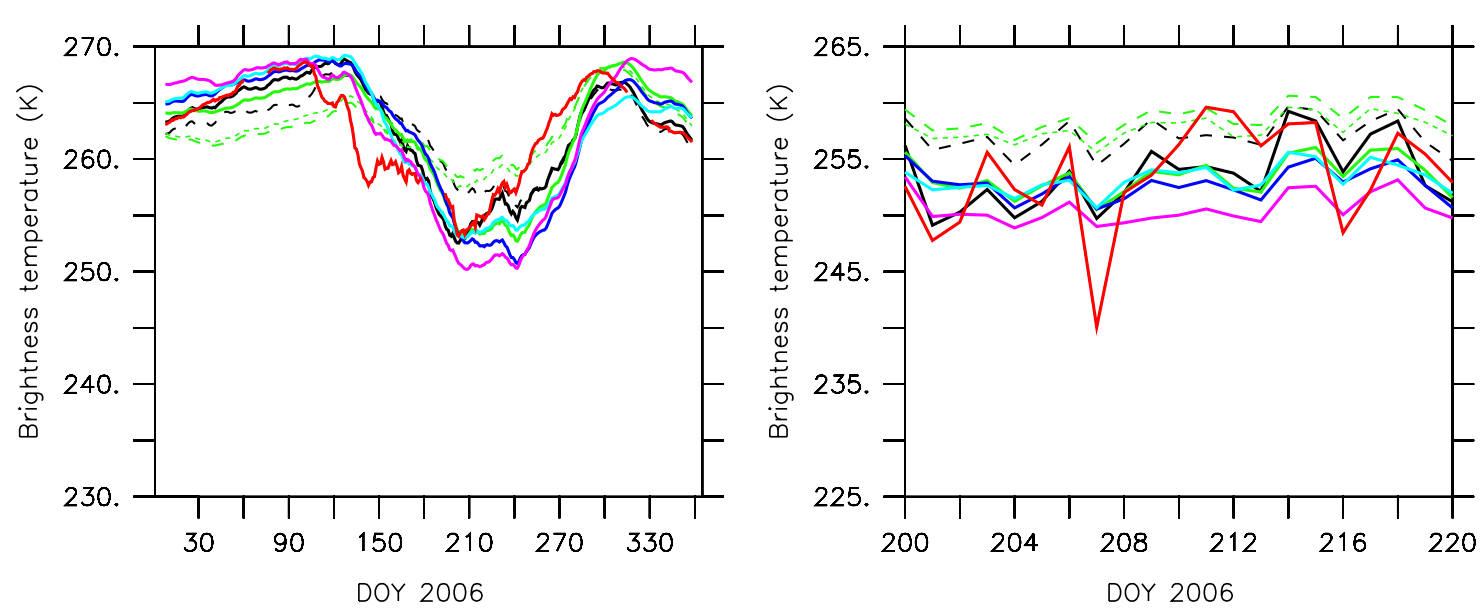

(b) South $\left(9-15^{\circ} \mathrm{N}\right)$

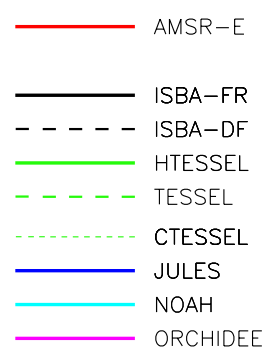

Figure 4. Temporal evolution (time in DOY) of simulated and observed horizontally polarized brightness temperature $(\mathrm{K})$ from the eight ALMIP-MEM simulations (CMEM configuration 10 of Table 1). Brightness temperatures are spatially averaged for the (a) north and (b) south of the studied window. (left) Annual cycle with a running average of 15 days. (right) Variability on shorter temporal scale is depicted between DOY 200 and 220. For each LSMs, a bias correction was applied on the basis of the mean annual mean bias computed on each subwindow.

DOY 231 leads to a drastic increase of observed soil moisture from very dry conditions on DOY 230 to wet conditions on DOY 231 , followed by a rapid decrease on DOY 232 due to the high infiltration rate of the sandy soil in the area.

[49] The soil moisture evolution is very well captured by most of the LSMs, which also validates the precipitation forcing in terms of date of occurrence and intensity. There is however a large scatter in simulated soil moisture values between the LSMs. JULES, ISBA-DF tend to underestimate soil moisture values while TESSEL, CTESSEL, ORCHIDEE-
CWRR overestimate soil moisture values. ISBA-FR and HTESSEL perform well on this site, and Noah underestimates the dynamics with overestimation of soil moisture in dry conditions and underestimation in wet conditions. The scatter in soil temperature conditions is much lower than that of brightness temperatures. Observed AMSR-E horizontal TB show a $55 \mathrm{~K}$ decrease between DOY 203 and 231. The decrease is very well simulated by most of the LSMs, with however a large scatter in TB values. The scatter is about $45 \mathrm{~K}$ in dry conditions and $25 \mathrm{~K}$ in wet conditions. For each 
(a)

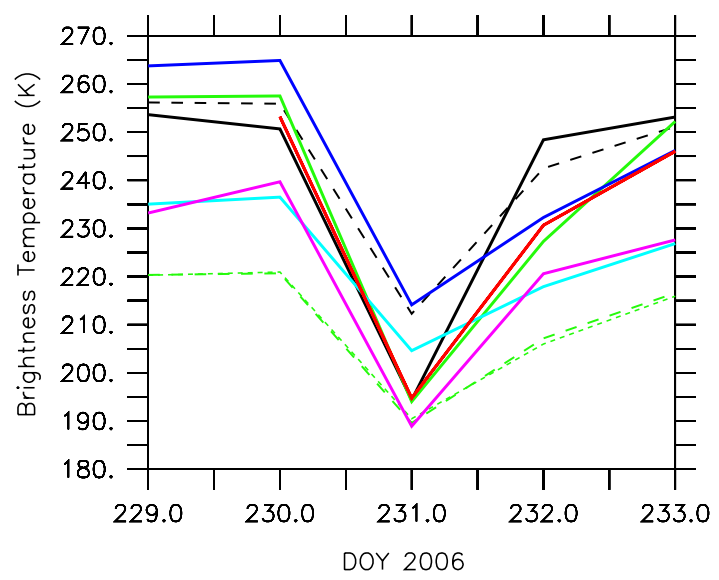

(c)

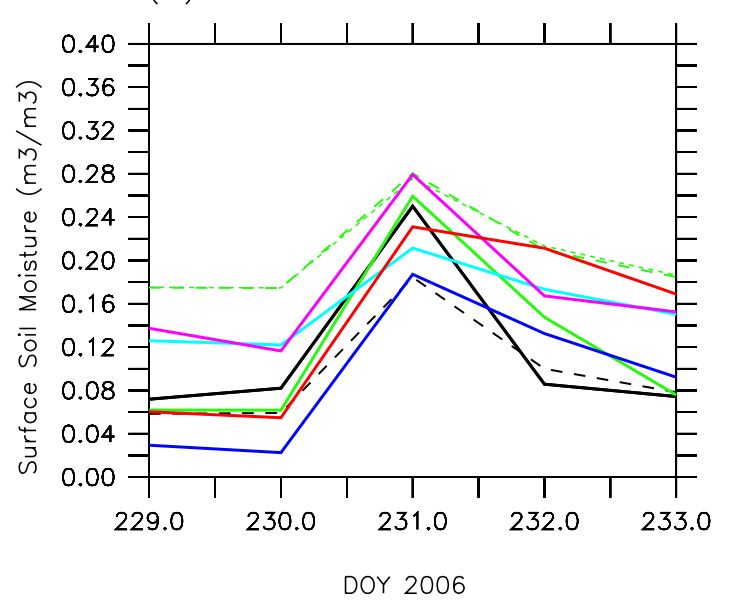

(b)
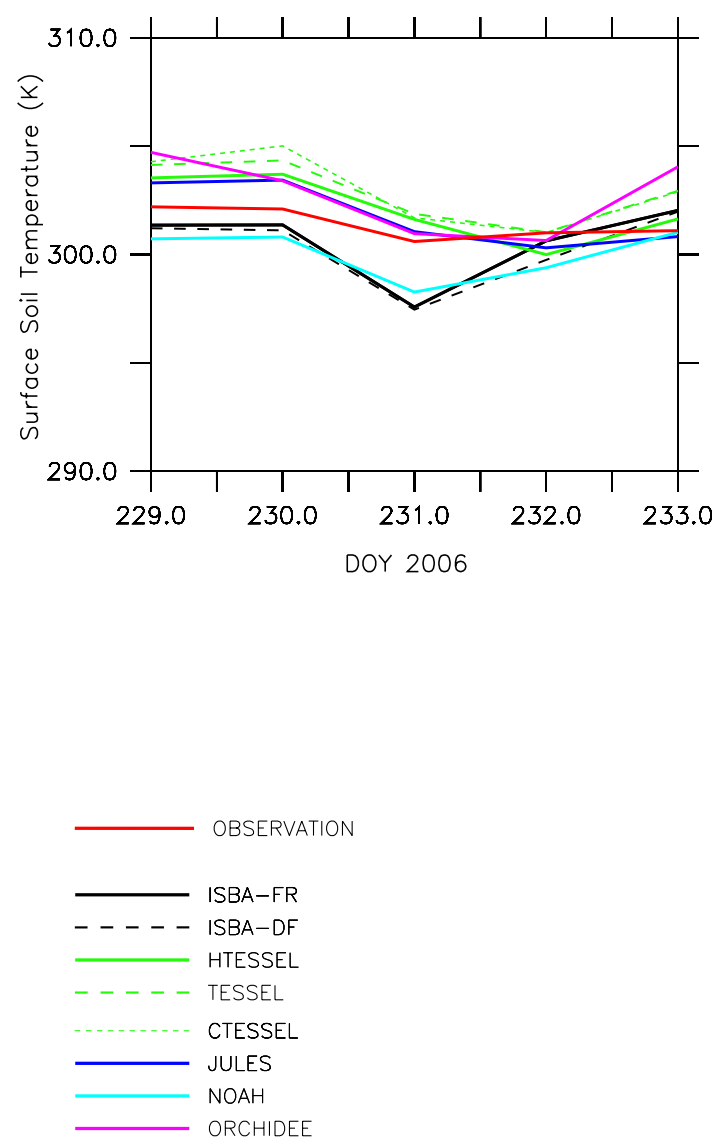

Figure 5. Temporal evolution of simulated and observed (a) horizontal brightness temperature, (b) surface soil temperature, and (c) surface soil moisture at $5 \mathrm{~cm}$ depth, between DOY 229 and 233 (17-21 August). Brightness temperature observations are AMSR-E C-band data. Soil moisture and soil temperatures observations are field measurements obtained on the Agoufou super site at $15.3^{\circ} \mathrm{N}, 1.5^{\circ} \mathrm{W}$ [de Rosnay et al., 2009]. Simulated TB are obtained with the configuration 10 of Table 1.

LSM, errors in simulated soil moisture are translated into errors in simulated TB. On DOY 231, in wet conditions, models which underestimate surface soil moisture (ISBA-DF, JULES, and Noah) overestimate TB values. ISBA-FR and HTESSEL simulate soil moisture values in agreement with field observations and provide horizontal TB in good agreement with AMSR-E data. In contrast, LSMs that overestimate soil moisture underestimate TB.

\subsection{Time-Latitude Distribution}

[50] Time-latitude diagrams in Figure 6 show 10-day mean brightness temperature of C-band horizontal polarization for both AMSR-E observations and simulations from the eight LSMs listed in Table 3 (with CMEM configuration 10). AMSR-E C-band data show a wet patch over the Sahel during the rainy season, centered DOY 210 and latitude $15.5^{\circ}$ north. This wet patch is reproduced by all the LSMs, but the amplitude is either overestimated or underestimated depending on the LSM. In agreement with Figure 4 (left), Figure 6 underlines the general good agreement for most LSMs between the forward approach and the satellite data at the annual cycle scale.

\subsection{Relative Role of LSMs and Microwave Emission Models}

[51] Figure 7 shows the latitudinal plot of simulated and observed horizontal brightness temperatures averaged for the monsoon season July-August-September (JAS). It considers the simulations performed in the configuration 10 of CMEM (Table 1), but in contrast to Figures 4 and 6 no bias correction has been applied to this plot.

[52] From $7^{\circ} \mathrm{N}$ to about $12^{\circ} \mathrm{N}$, there is a generally good agreement between the simulated and observed TB. The scatter between the LSMs is very low, which indicates that the different soil moisture and soil temperature patterns simulated by the LSMs do not affect much the signal. Rather, this indicates that the vegetation plays a dominant role in the determination of TB.

[53] From $12^{\circ} \mathrm{N}$ to $16^{\circ} \mathrm{N}$ the latitudinal gradient is characterized by a decrease in both vegetation cover and soil moisture which have opposite effects on the simulated TB. The observed decrease in TB indicates that the vegetation contribution still dominates the signal. The simulations reproduce this latitudinal decrease in $\mathrm{TB}$, although it is 

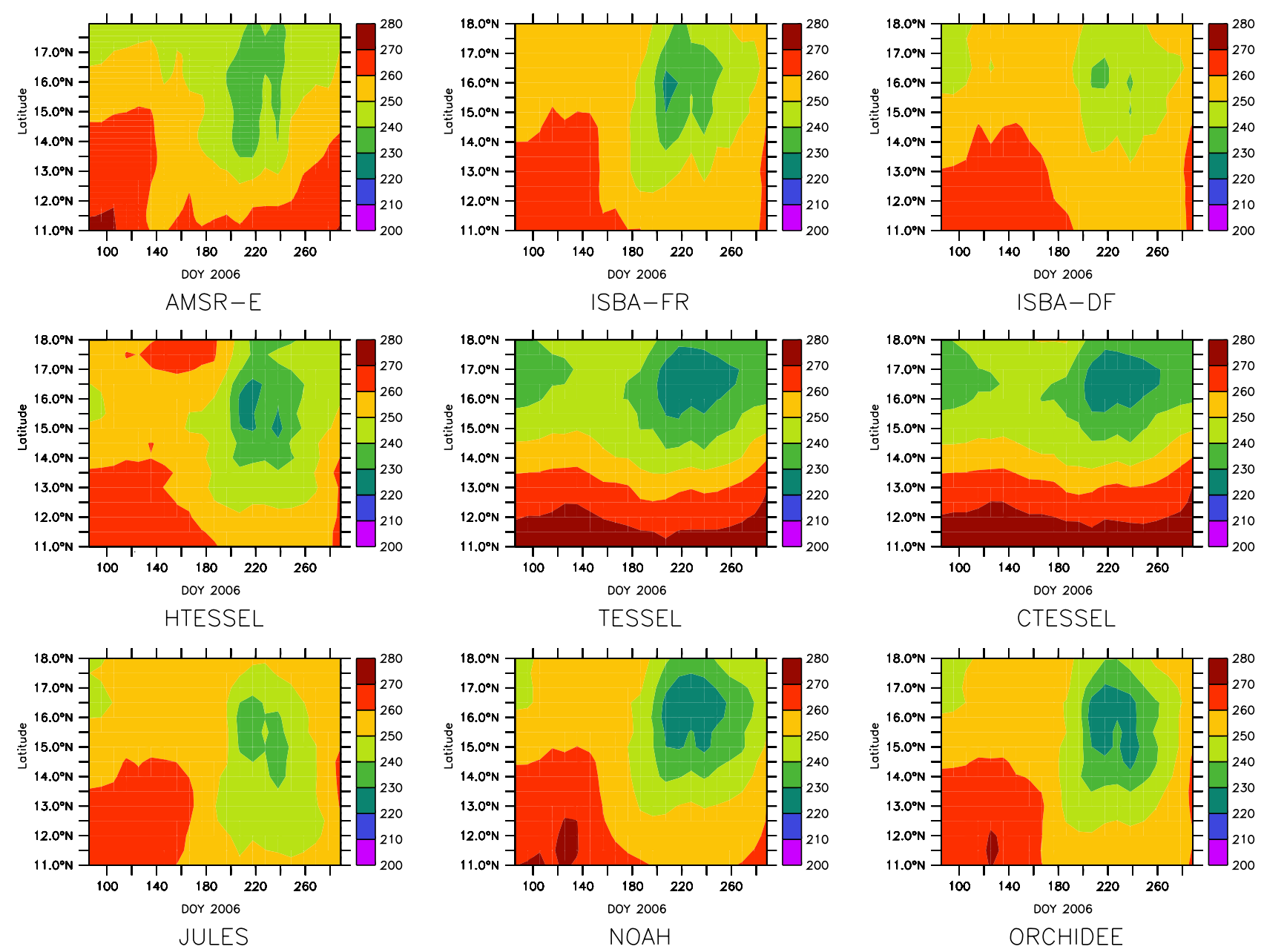

Figure 6. Time-latitude diagram of the horizontally polarized brightness temperature (K) observed by AMSR-E and simulated by ALMIP-MEM (CMEM configuration 10 of Table 1). For each ALMIP-MEM simulation a bias correction was applied according to Table 4.

overestimated by some of the models. The scatter between the models is increasing with latitude, as the relative contribution of soil emission becomes more important. It reaches a maximum amplitude $(40 \mathrm{~K})$ at $16^{\circ} \mathrm{N}$. The strong negative

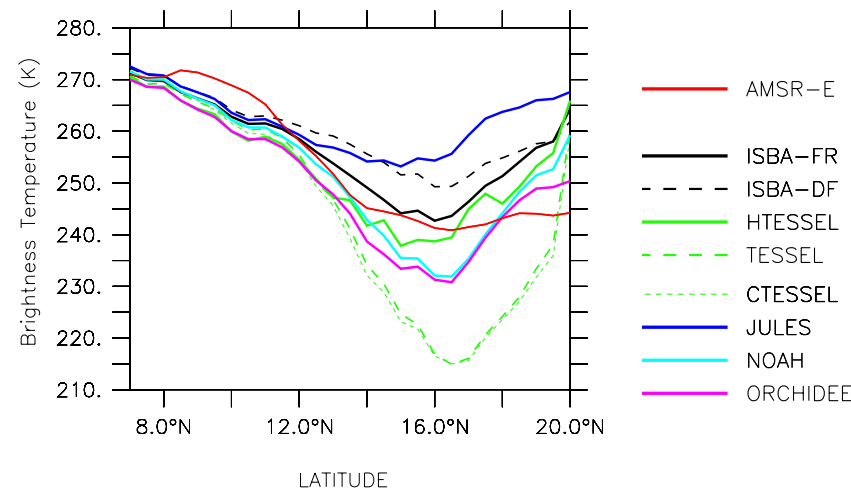

Figure 7. Zonal distribution of observed and simulated brightness temperatures $(\mathrm{K})$ at horizontal polarization, averaged over July August, and September, for the eight ALMIPMEM LSMs coupled to CMEM using Wang and Schmugge and Kirdyashev models (CMEM configuration 10 of Table 1). bias of TESSEL and CTESSEL over Sahel is due to an overestimation of soil moisture by these models. Accounting for soil texture in HTESSEL leads to simulation of TB in a better agreement with the other LSMs and with the observations.

[54] From $16^{\circ} \mathrm{N}$ to $20^{\circ} \mathrm{N}$, simulated TB increases for all the LSMs. For all of them this corresponds to a latitudinal decrease in soil water content. In contrast, AMSR-E observations do not show any latitudinal gradient in this range of latitude, indicating the end of the transition zone to the desert area.

[55] The latitudinal distribution of simulated and observed horizontal TB is shown Figure 8 for the 8 LSMs and for the 12 CMEM configurations. For each LSM, the scatter due to microwave emission model configuration is as important as the scatter shown in Figure 7 for one microwave model and several LSMs. It reaches about $40 \mathrm{~K}$ at $10^{\circ} \mathrm{N}$ for most of the LSMs. In contrast to that obtained for different LSMs, the scatter due to the microwave emission model is more important for southern latitudes where it is related to the vegetation opacity model. Above $12^{\circ} \mathrm{N}$ vegetation cover decreases, and the scatter due to the opacity model decreases until the latitude $16^{\circ} \mathrm{N}$ is reached. Despite of the large scatter shown between the microwave emission models, it is interesting to notice that the results obtained by the Wigneron's opacity model are very close to those obtained with the Wegmüller 


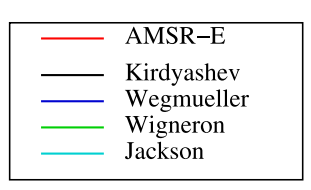

(c) HTESSEL

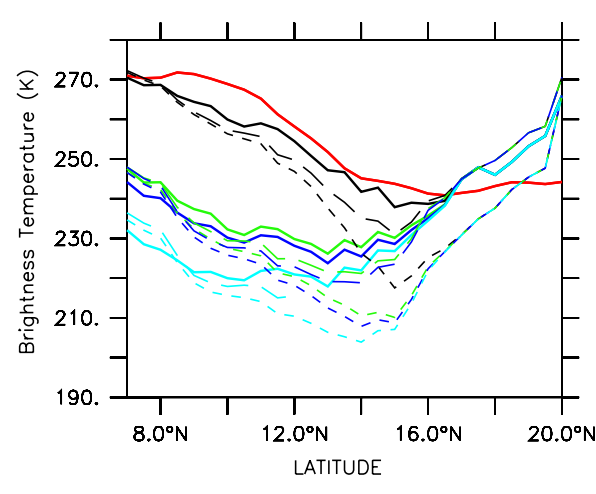

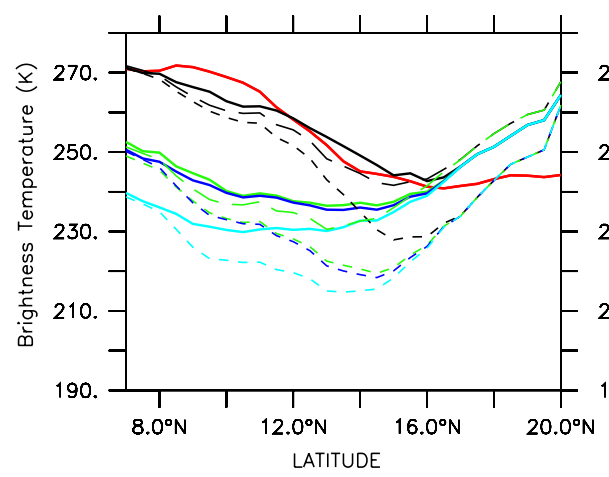

(a) ISBA-FR

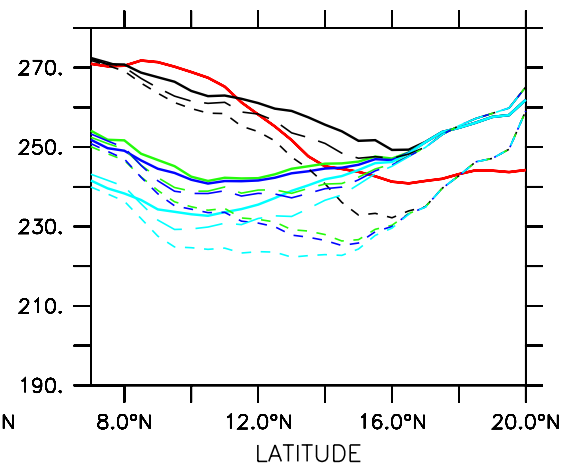

(b) ISBA-DF

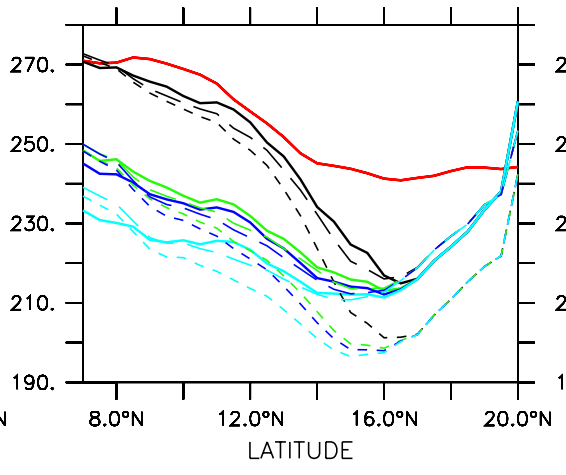

(d) TESSEL

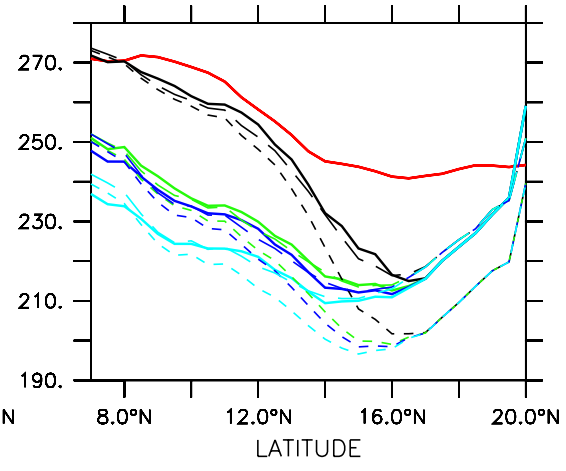

(e) CTESSEL

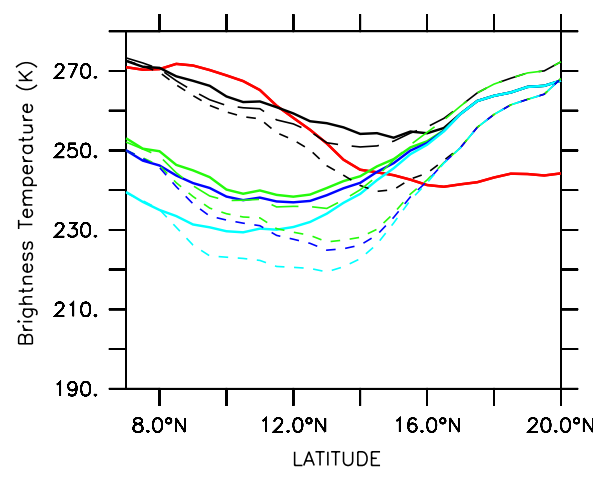

(f) JULES

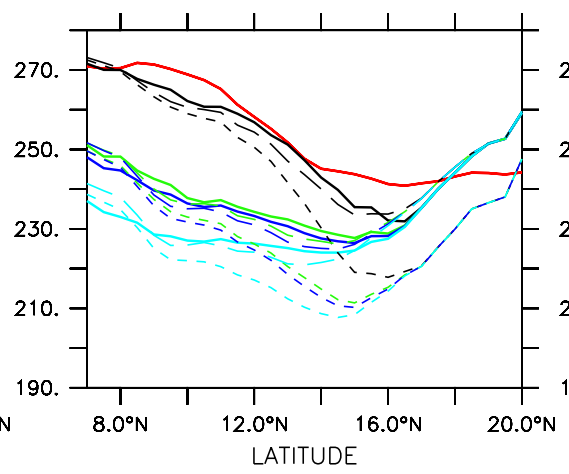

(g) NOAH

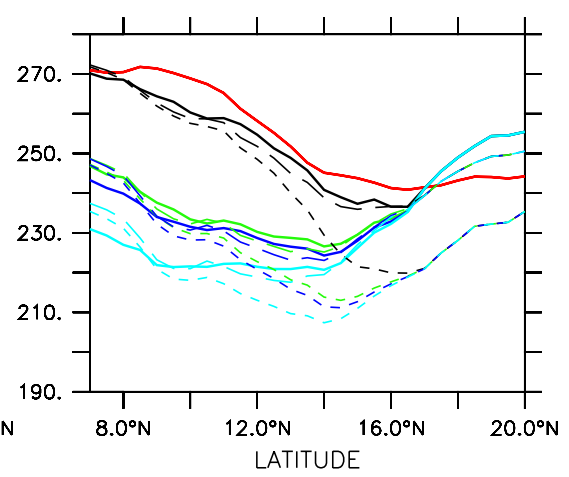

(h) ORCHIDEE-CWRR

Figure 8. Zonal distribution of observed and simulated brightness temperatures $(\mathrm{K})$ at horizontal polarization, for the eight ALMIP-MEM LSMs. For each LSM, brightness temperatures have been simulated for the 12 configurations of CMEM given in Table 1. Line color indicates the vegetation model and line style indicates the dielectric model: solid line for Wang and Schmugge, dashed line for Mironov, and dotted line for Dobson.

model. For any LSM considered in this study, the Kirdyashev opacity model (black lines) is shown in Figure 8 to be the closest to the AMSR-E observations for the JAS average. This result must be taken with care because it might be sensitive to uncertainties related to the vegetation data base which is used [Holmes et al., 2008]. However the robustness of the good performances of the Kirdyashev among the different LSMs is noteworthy. North to $16^{\circ} \mathrm{N}$ there is no more vegetation in the ALMIP simulations and the scatter in simulated TB is due to the dielectric model only. Therefore the 12 microwave models converge to 3 microwave models which differ in their parameterization of the soil dielectric constant.
[56] Along the north-south gradient, the scatter due to the soil dielectric model is lower than that resulting from vegetation opacity. It is increasing with the latitudinal decrease of vegetation density. For any LSM and any latitude the Wang and Schmugge model (Figure 8, solid lines) leads to higher brightness temperatures than the Dobson model (Figure 8, dotted lines). The Mironov model (Figure 8, dashed lines) provides intermediate values close to those of the Wang and Schmugge model.

[57] Figures 9 and 10 are the Taylor diagrams obtained for ALMIP-MEM simulated brightness temperatures (horizontal polarization), for each of the 8 LSMs for the 12 microwave modeling configurations.For each LSM, the range of 


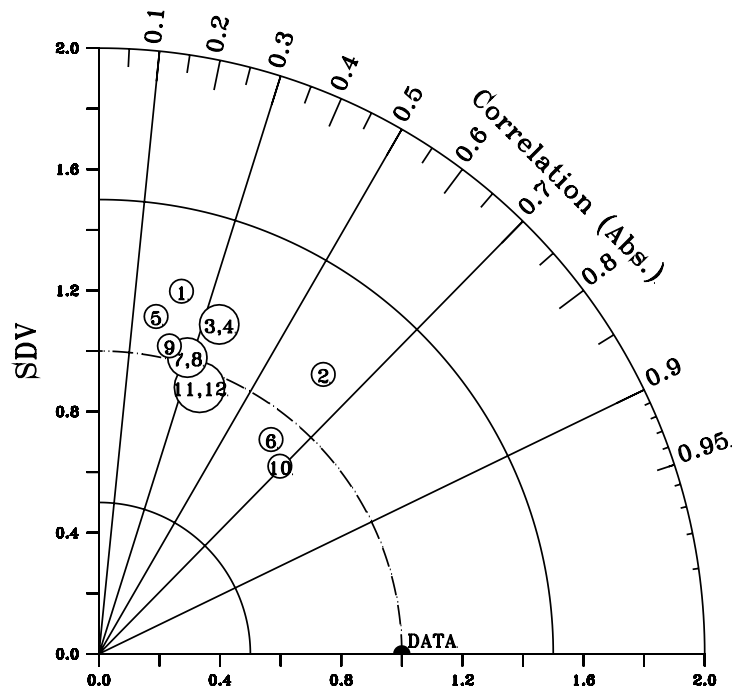

(a) ISBA-FR

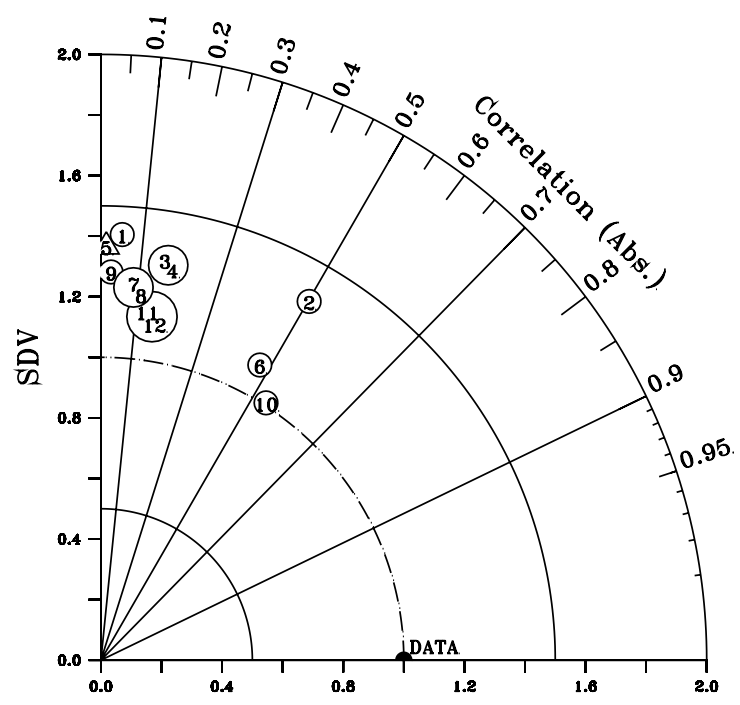

(c) HTESSEL

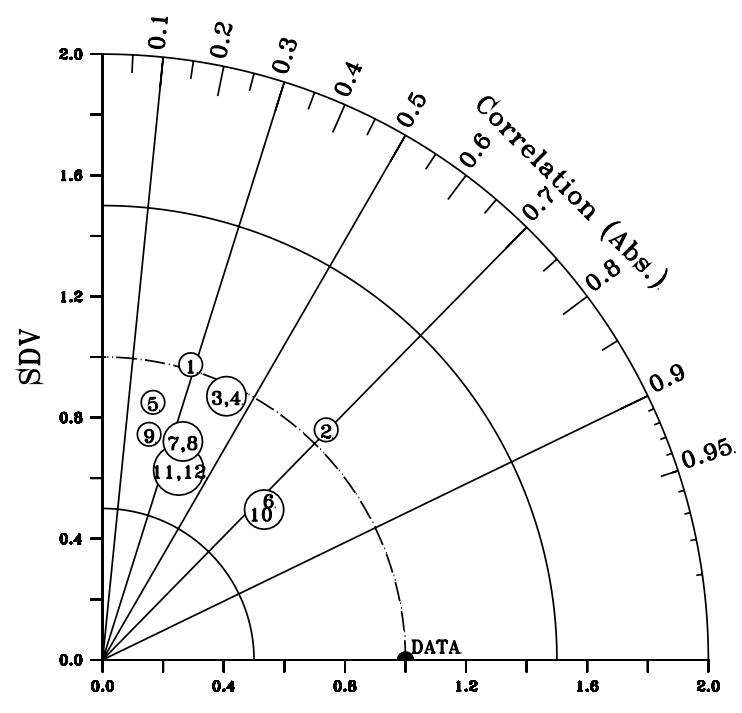

(b) ISBA-DF

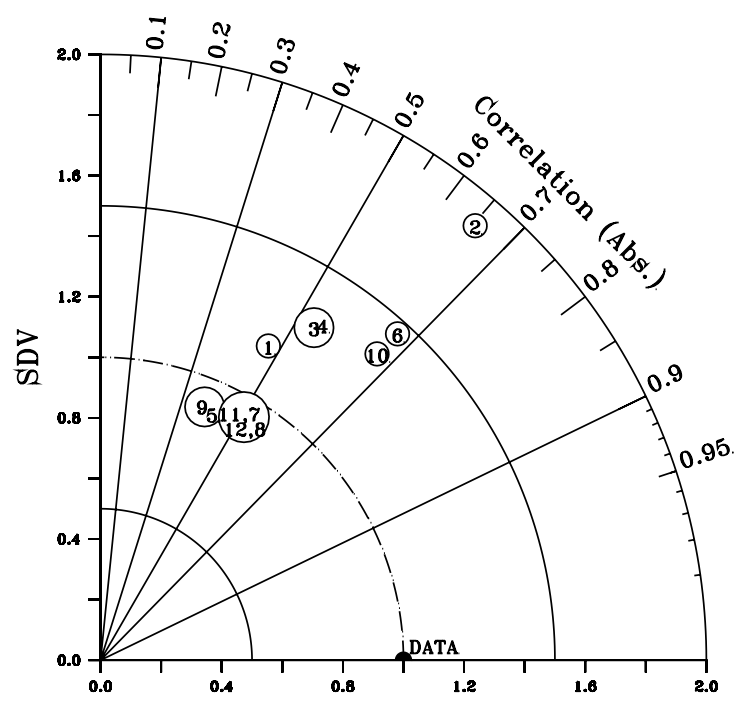

(d) TESSEL

Figure 9. Taylor diagram illustrating the statistics of the comparison between ALMIP-MEM synthetic brightness temperature and AMSR-E data at C-band for (a) ISBA-FR, (b) ISBA-DF, (c) HTESSEL, and (d) TESSEL coupled to CMEM using the 12 different configurations of the microwave emission modeling defined in Table 1. Note that the radial axis is different from that of Figure 2. Triangle denotes negative correlation, while circles correspond to positive correlation. The number within each circle indicates the configuration listed in Table 1.

correlation values between simulated and observed TB is very large, indicating that the spatiotemporal correlation between simulated and observed TB is very sensitive to the choice of the microwave emission model.

[58] In term of SDV, most LSMs gets best performances using the Kirdyashev model (configurations 2, 6, and 10). But the best dielectric model varies with the LSM. Figures 9 and 10 clearly show that the scatter in SDV is largely influenced by the choice of dielectric model. For any LSM, the Dobson dielectric model (configurations 1, 2, 3, and 4) leads to a larger amplitude of the signal than the Mironov (configurations 5, 6, 7, and 8) or the Wang and Schmugge (configurations 9, 10,11, and 12) models. For JULES and ISBA-DF which underestimate the SDV, the use of the Dobson model (configurations 1, 2, 3, and 4) improves the representation of the simulated SDV (Figures $9 \mathrm{~b}$ and $10 \mathrm{~b}$ ). In contrast, ISBA-FR, HTESSEL, Noah and ORCHIDEECWRR perform better in terms of SDV using Wang and Schmugge or Mironov than Dobson (Figures 10c and 10d). TESSEL and CTESSEL overestimate the simulated amplitude. For these two LSMs the best SDV and $E$ is obtained with the Wegmüller and Wigneron models with Mironov 


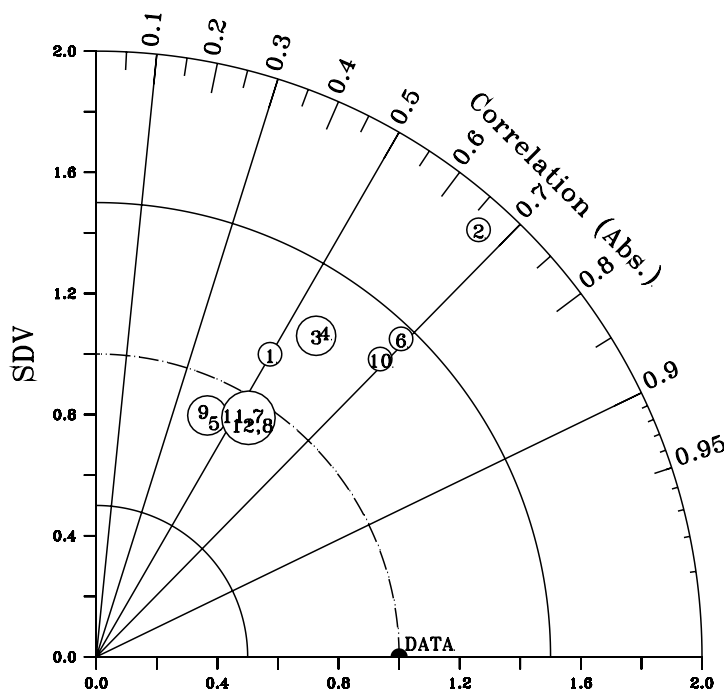

(a) CTESSEL

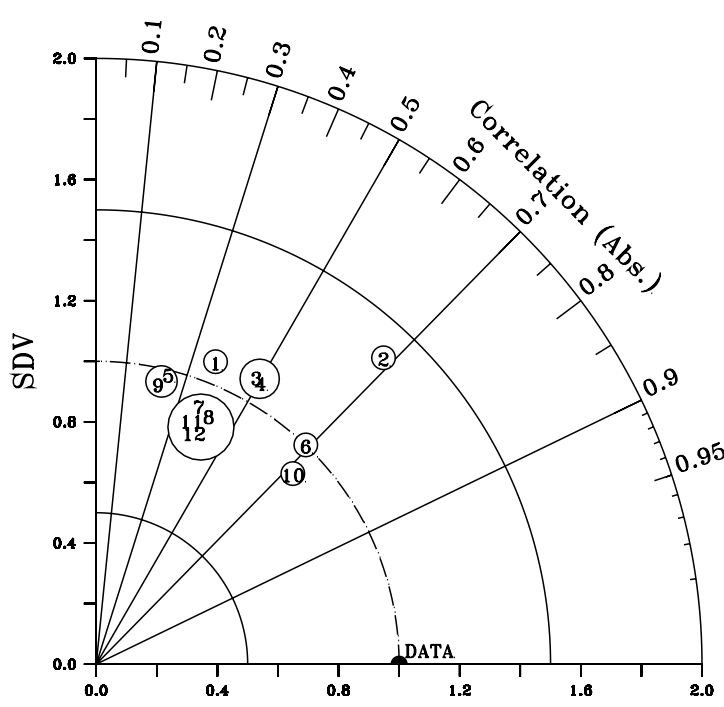

(c) $\mathrm{NOAH}$

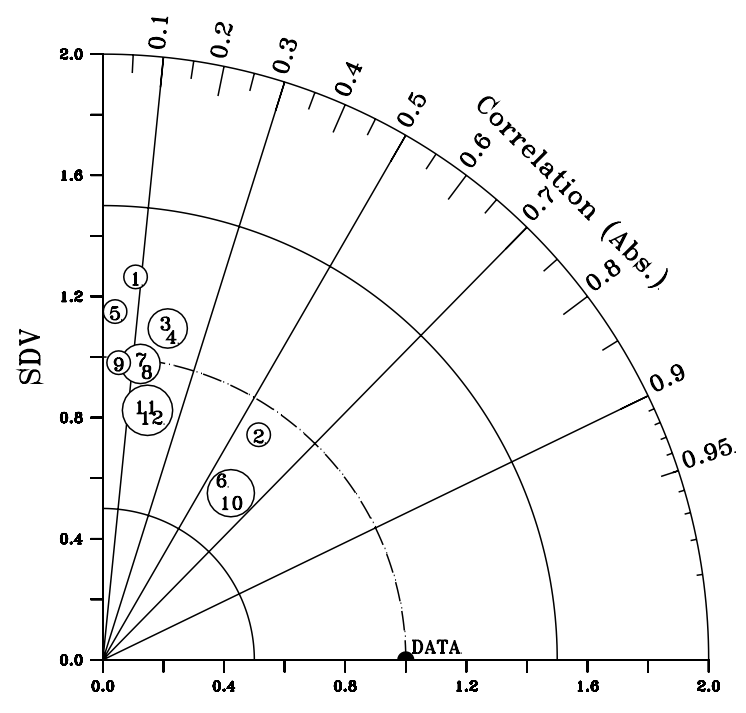

(b) JULES

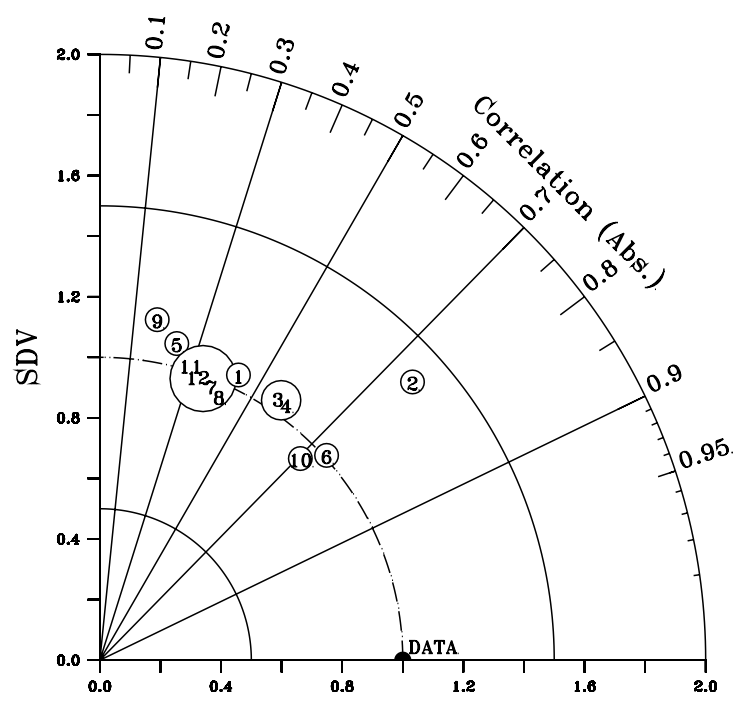

(d) ORCHIDEE-CWRR

Figure 10. Same as Figure 9, but for (a) CTESSEL, (b) JULES, (c) Noah, and (d) ORCHIDEE-CWRR.

(configurations 7 and 8). However, the Kirdyashev model with Mironov and Wang and Schmugge models (configurations 6 and 10) leads to best correlation values.

[59] In terms of correlation, Figures 9 and 10 show that the choice of vegetation opacity model strongly affects the performances in terms of correlation. For any LSM, best correlation values are obtained by the Kirdyashev model (configurations 2, 6, and 10). In particular, the microwave emission modeling configuration 10 provides best agreement with the AMSR-E data for almost all the LSMs, except for ORCHIDEE-CWRR for which the configuration 6 of CMEM, with the Mironov dielectric model, provides slightly better results than the configuration 10 with the Wang and Schmugge model.

[60] The best microwave modeling configuration obtained for each LSM is indicated in Table 5 with regard to the three statistical indexes used in this study $(R, E$, and SDV). Except for TESSEL and CTESSEL, the best microwave modeling configurations are shown to be the CMEM models 10, 6, and 2. They all correspond to the Kirdyashev opacity model with Wang and Schmugge, Mironov and Dobson dielectric models, respectively.

[61] The robustness of the Kirdyashev model to simulate brightness temperatures in best agreement with the satellite observations is particularly noteworthy. For most LSMs considered, with corresponding errors on soil moisture and soil temperature patterns, it simulates the brightness temperatures dynamics with lowest errors and highest correlation.

\section{Summary and Conclusion}

[62] ALMIP-MEM consists of a set of simulations of C-band brightness temperatures over West Africa for one annual cycle in 2006. Simulations have been performed for an incidence angle of $55^{\circ}$ and results are evaluated against 
Table 5. Best Microwave Emission Modeling Configuration, as Indexed in Table 1, for Each ALMIP-MEM LSM and for Each Statistical Index ${ }^{\mathrm{a}}$

\begin{tabular}{lccc}
\hline \multicolumn{1}{c}{ LSM } & $R$ & $E$ & SDV \\
\hline ISBA-FR & 10 & 10 & 6 \\
ISBA-DF & 10 & 10 & 2 \\
HTESSEL & 10 & 10 & 10 \\
TESSEL & $6 / 10$ & 8 & $7 / 8$ \\
CTESSEL & $6 / 10$ & 8 & $7 / 8$ \\
JULES & 10 & 10 & 2 \\
Noah & 10 & 10 & 6 \\
ORCHIDEE & 6 & 6 & 6 \\
\hline
\end{tabular}

${ }^{a}$ For SDV, best microwave emission model is chosen among those presenting a correlation value larger than 0.5. For TESSEL and CTESSEL, two models provide best agreement with the observation in terms of correlation.

AMSR-E C-band data. The study encompasses 96 simulations, for 8 LSMs coupled to the Community Microwave Emission Model in 12 configurations. Each configuration corresponds to a different combination of the vegetation opacity and the soil dielectric models. Simulations are performed for the ALMIP experiment for which LSMs forcing result from merged atmospheric variables (ECMWF-FC), precipitation (EPSAT-SG) and radiative fluxes (SAF-land).

[63] The best CMEM configuration is generally the one that uses the Kirdyashev opacity model and the Wang and Schmugge dielectric model. The spatiotemporal correlation between simulated and observed TB, averaged among the $8 \mathrm{LSMs}$ is 0.67 . The $8 \mathrm{LSMs}$ coupled to CMEM reproduce particularly well the annual cycle of the signal, for both the northern and southern portions of the studied window. This provides an indirect validation of the LSMs and the meteorological forcing at this temporal scale. This also validates the microwave emission modeling approach which allows the representation of the correct seasonal amplitude of the C-band signal in contrasting soil, vegetation, and atmosphere conditions.

[64] For the Sahelian area, a case study is conducted to compare model performances over the Agoufou super site at short temporal scale when a typical convective rainfall event occurs. The LSMs perform well to reproduce the fast variations of soil moisture. But the various LSMs perform differently in terms of absolute value and in terms of amplitude of the simulated soil moisture. LSMs errors in simulated soil moisture impact on simulated brightness temperatures. This triangular comparison between our simulations of soil moisture and TB with field and AMSR-E data provides a validation of the precipitation forcing, the LSMs and the microwave emission model on this pixel and at the precipitation event timescale.

[65] At seasonal range, it is shown that the time-latitude pattern is well reproduced by all the LSMs coupled to CMEM (configuration 10), with a good agreement with AMSR-E data. A wet patch characterized by lower values of brightness temperatures at horizontal polarization is observed and simulated over Sahel in August which is the period of maximum activity of the monsoon season.

[66] ALMIP-MEM provides the first intercomparison of microwave emission models at regional scale. Combined with the ALMIP LSM intercomparison, the study quantifies the relative importance of Land Surface Modeling and radiative transfer modeling in the monitoring of low-frequency passive microwave emission on land surfaces. The scatter obtained between the various LSMs is an evidence that land surface modeling has an impact on the simulated brightness temperature. Although they all use the same atmospheric forcing, the various LSMs use different parameterizations, eg of the vertical soil moisture diffusion, vegetation seasonality, plant water uptake in the soil layers and evapotranspiration, surface roughness and albedo. These differences between the various LSMs parameterizations, lead to differences in simulated fluxes and soil moisture. Resulting simulated brightness temperatures differ between the LSMs. LSMs that take into account a fine vertical discretization near the surface in the soil do an overall better job than those which use a coarser resolution to reproduce the AMSR-E brightness temperatures. Accounting for soil texture in the land surface models also largely impacts on the simulated brightness temperature, as shown by comparing HTESSEL and TESSEL simulations.

[67] A large sensitivity in simulated TOA brightness temperature is also shown to be due to the choice of the forward modeling approach. The dielectric model has a high impact on the amplitude of variations (SDV) of simulated TB. For any LSM and any vegetation opacity model, the Dobson parameterization of the dielectric constant leads to higher SDV than the Wang and Schmugge parameterization. Results of the Mironov model are close to those obtained with the Wang and Schmugge model. The vegetation opacity model is the largest factor affecting the correlation skill of the coupled LSM-CMEM to simulate TOA TB. Statistical results show the suitability and the robustness of the Kirdyashev opacity model which, when used here with the ECOCLIMAP vegetation database, provides best results for most LSMs considered in this study. For all LSMs, the combination of the Kirdyashev model with the Wang and Schmugge dielectric model leads to best performances in simulated TB in terms of correlation.

[68] In the framework of the preparation of the future SMOS satellite, the large sensitivity of simulated TOA TB to the choice of the microwave emission model, as well as the consistence of the results obtained for different LSMs to identify a best microwave modeling approach, point out the importance of the forward modeling approach for soil moisture retrieval and assimilation of passive microwave data.

[69] Acknowledgments. This work has been supported by the ECMWF and the European Space Agency (ESA) under the contract 20244/07/I-LG for the preparation of the Soil Moisture and Ocean Salinity (SMOS) mission project. The authors thank the NASA National Snow and Ice Data Center (NSIDC) for providing AMSR-E brightness temperature data. The AMMA (African Monsoon Multidisciplinary Analysis) Land Surface Model Intercomparison Project has been conducted in the framework of AMMA. On the basis of a French initiative AMMA was built by an international scientific group and is currently funded by a large number of agencies, especially from France, U.K., United States, and Africa. It has been the beneficiary of major financial contribution from the European Community's Sixth Framework Research Programme. Detailed information in scientific coordination and funding is available on the AMMA International web site http://www.amma-international.org. The authors thank Erik Andersson for his helpful comments on the manuscript.

\section{References}

Balsamo, G., P. Viterbo, A. Beljaars, B. van den Hurk, M. Hirsch, A. Betts, and K. Scipal (2009), A revised hydrology for the ECMWF model: Verification from field site to terrestrial water storage and impact in the Itegrated Forecast System, J. Hydrometeorol., in press.

Blyth, E., M. Best, P. Cox, R. Essery, O. Boucher, R. Harding, C. Prentice, P. Vidale, and I. Woodward (2006), JULES: A new community land surface model, Global Change Newsl., 66, 1-11. 
Boone, A., V. Masson, T. Meyers, and J. Noilhan (2000), The influence of the inclusion of soil freezing on simulations by a soilvegetationatmosphere transfer scheme, J. Appl. Meteorol., 39(9), 1544-1569.

Calvet, J.-C., J. Noilhan, J.-L. Roujean, P. Bessemoulin, M. Cabelguenne, A. Olioso, and J.-P. Wigneron (1998), An interactive vegetation SVAT model tested against data from six contrasting sites, Agric. For. Meteorol., $37,73-95$.

Calvet, J.-C., A.-L. Gibelin, J.-L. Roujean, E. Martin, P. Le Moigne, H. Douville, and J. Noilhan (2008), Past and future scenarios of the effect of carbon dioxide on plant growth and transpiration for three vegetation types of southwestern France, Atmos. Chem. Phys., 8, 397-406.

Chen, F., and J. Dudhia (2001), Coupling an advanced land surface-hydrology model with the Penn State NCAR MM5 modeling system. Part I: Model implementation and sensitivity, Mon. Weather Rev., 129, 569-585.

Chopin, F., J. Berges, M. Desbois, I. Jobard, and T. Lebel (2004), Multiscale precipitation retrieval and validation in african monsoon systems, paper presented at 2nd International TRMM Science Conference, Jpn. Aerospace Explor. Agency, Nara, Japan.

Choudhury, B., T. Schmugge, A. Chang, and R. Newton (1979), Effect of surface roughness on the microwave emission from soils, J. Geophys. Res., 84, 5699-5706.

Choudhury, B., T. Schmugge, and T. Mo (1982), A parameterization of effective soil temperature for microwave emission, J. Geophys. Res., $87,1301-1304$.

Ciais, P., et al. (2005), Europe-wide reduction in primary productivity caused by the heat and drought in 2003, Nature, 437, 529-533, doi:10.1038/nature03972.

Decharme, B. (2007), Influence of the runoff representation on continental hydrology using the Noah and the ISBA land surface models, J. Geophys. Res., 112, D19108, doi:10.1029/2007JD008463.

de Rosnay, P., J. Polcher, M. Bruen, and K. Laval (2002), Impact of a physically based soil water flow and soil-plant interaction representation for modeling large-scale land surface processes, J. Geophys. Res., 107(11), 4118, doi:10.1029/2001JD000634.

de Rosnay, P., et al. (2006), SMOSREX: A long term field campaign experiment for soil moisture and land surface processes remote sensing, Remote Sens. Environ., 102, 377-389, doi:10.1016/j.rse.2006.02.021.

de Rosnay, P., C. Gruhier, F. Timouk, F. Baup, E. Mougin, P. Hiernaux, L. Kergoat, and V. Le Dantec (2009), Multi-scale soil moisture measurements over the Gourma meso-scale site in Mali, J. Hydrol., 1, doi:10.1016/ j.jhydrol.2009.01.015, in press.

Dirmeyer, P. A., A. Dolman, and N. Sato (1999), The pilot phase of the Global Soil Wetness Project, Bull. Am. Meteorol. Soc., 80, 851-878.

Dirmeyer, P. A., X. Gao, Z. Guo, T. Oki, and N. Hanasaki (2006), The Second Global Soil Wetness Project (GSWP-2): Multi-model analysis and implications for our perception of the land surface, Bull. Am. Meteorol. Soc., 87, 1381-1397.

Dobson, M., F. Ulaby, M. Hallikainen, and M. El-Rayes (1985), Microwave dielectric behavior of wet soil-partii: Dielectric mixing models, IEEE Trans Geosc. Sci. Remote Sens., 38, 1635-1643.

d'Orgeval, T., J. Polcher, and P. de Rosnay (2008), Sensitivity of the West African hydrological cycle in ORCHIDEE to infiltration processes, Hydrol. Earth Syst. Sci., 12, 1387-1401.

Drusch, M., E. Wood, and T. Jackson (2001), Vegetative and atmospheric corrections for soil moisture retrieval from passive microwave remote sensing data: Results from the Southern Great Plains Hydrology Experiment 1997, J. Hydrometeorol., 2, 181-192.

Drusch, M., T. Holmes, P. de Rosnay, and G. Balsamo (2009), Comparing ERA-40 based L-band brightness temperatures with Skylab observations: A calibration/validation study using the Community Microwave Emission Model, J. Hydrometeorol., 1, doi:10.1175/2008JHM964.1, in press.

Entekhabi, D., et al. (1999), An agenda for land surface hydrology research and a call for the second international hydrological decade, Bull. Am. Meteorol. Soc., 10, 2043-2058.

Essery, R. L. H., M. Best, R. Betts, P. Cox, and C. M. Taylor (2003), Explicit representation of subgrid heterogeneity in a GCM land surface scheme, J. Hydrometeorol., 4, 530-543.

Foley, J., I. Prentice, N. Ramankutty, S. Levis, D. Pollard, S. Sitch, and A. Haxeltine (1996), An integrated biosphere model of land surface processes, terrestrial carbon balance and vegetation dynamics, Global Biogeochem. Cycles, 10, 603-628.

Gao, X., P. Dirmeyer, Z. Guo, M. Zhao, B. Decharme, G. Niu, and S. Mahanama (2004), An approach for remote sensing validation of land surface scheme on a global scale, COLA Tech. Rep. 173, 42 pp., Cent. for Ocean-Land-Atmos. Stud., Calverton, Md.

Geiger, B., C. Meurey, D. Lajas, L. Franchistéguy, D. Carrer, and J.-L. Roujean (2008), Near real-time provision of downwelling shortwave radiation estimates derived from satellite observations, Meteorol. Appl., 15, 411-420, doi:10.1002/met.84.
Gruhier, C., P. de Rosnay, Y. Kerr, E. Mougin, E. Ceschia, J.-C. Calvet, and P. Richaume (2008), Evaluation of AMSR-E soil moisture products based on ground soil moisture network measurements, Geophys. Res. Lett., 35, L10405, doi:10.1029/2008GL033330.

Hall, F., B. Meeson, S. Los, and E. Brown de Colstoun (2001), ISLSCP II: New $10+$ year multi-parameter near-surface global data set including greater carbon and vegetation data, GEWEX Newsl., 11(2), 12-13.

Henderson-Sellers, A., A. Pitman, P. Love, P. Irannejad, and T. Chen (1995), The project for inter-comparison of land-surface parametrization schemes (PILPS): Phase 2 and 3, Bull. Am. Meteorol. Soc., 76, 489-503.

Holmes, T., M. Drusch, J.-P. Wigneron, and R. de Jeu (2008), A global simulation of microwave emission: Error structures based on output from ECMWFs operational Integrated Forecast System, IEEE Trans. Geosci. Remote Sens., 46, 846-856.

Jackson, T., and P. O'Neill (1990), Attenuation of soil microwave emission by corn and soybeans at 1.4 and $5 \mathrm{GHz}$, IEEE Trans. Geosci. Remote Sens., 28, 978-980.

Jackson, T., and T. Schmugge (1991), Vegetation effects on the microwave emission of soils, Remote Sens. Environ., 36, 203-212.

Jackson, T. J., D. M. Le Vine, A. Hsu, A. Oldack, P. Starks, C. Swift, J. Isham, and M. Haken (1999), Soil moisture mapping at regional scales using microwave radiometry: The Southern Great Plains Hydrology Experiment, IEEE Trans. Geosci. Remote Sens., 37, 2136-2149.

Janicot, S., et al. (2008), Large scale overview of the summer monsoon over West and central Africa during AMMA field experiment in 2006, Ann. Geophys., 26(9), 2569-2595.

Jarlan, L., G. Balsamo, S. Lafont, A. Beljaars, J.-C. Calvet, and E. Mougin (2007), Analysis of Leaf Area Index in the ECMWF land surface scheme and impact on latent heat and carbon fluxes: Applications to West Africa, Tech. Rep. 544, 33 pp., Eur. Cent. for Medium-Range Weather Forecasts, Reading, U. K.

Jones, A., T. Vukićević, and T. Vonder Haar (2004), A microwave satellite observational operator for variational data assimilation of soil moisture, J. Hydrometeorol., 5, 213-229.

Kerr, Y. H., and E. G. Njoku (1990), A semi empirical model for interpreting microwave emission from semiarid surfaces as seen from space, IEEE Trans. Geosci. Remote Sens., 28, 384-393.

Kerr, Y. H., P. Waldteufel, J.-P. Wigneron, J.-M. Martinuzzi, J. Font, and M. Berger (2001), Soil moisture retrieval from space: The Soil Moisture and Ocean Salinity (SMOS) mission, IEEE Trans. Geosci. Remote Sens., 39, 1729-1735.

Kirdyashev, K., A. Chukhlantsev, and A. Shutko (1979), Microwave radiation of the Earth's surface in the presence of vegetation cover, Radiotekh. Elektr., 24, 256-264.

Koster, R. D., et al. (2004), Regions of strong coupling between soil moisture and precipitation, Science, 305, 1138-1140.

Krinner, G., N. Viovy, N. de Noblet-Ducoudré, J. Ogée, J. Polcher, P. Friedlingstein, P. Ciais, S. Sitch, and I. Prentice (2005), A dynamic global vegetation model for studies of the coupled atmosphere-biosphere system, Global Biogeochem. Cycles, 19, GB1015, doi:10.1029/ 2003GB002199

Lettenmaier, D. (2003), Preface to PILPS special issue, Global Planet. Change, 38, vii-ix.

Li, L., E. G. Njoku, E. Im, P. S. Chang, and K. S. Germain (2004), A preliminary survey of radio-frequency interference over the U.S. in Aqua AMSR-E data, IEEE Trans. Geosci. Remote Sens., 42, 380-390.

Mahfouf, J.-F., K. Bergaoui, C. Draper, F. Bouyssel, F. Taillefer, and L. Taseva (2009), A comparison of two off-line soil analysis schemes for assimilation of screen-level observations, J. Geophys. Res., doi:10.1029/ 2008JD011077, in press.

Masson, V., J.-L. Champeaux, F. Chauvin, C. Meriguet, and R. Lacaze (2003), A global database of land surface parameters at $1-\mathrm{km}$ resolution in meteorological and climate models, J. Clim., 97, 1261-1282.

Milly, P. C. D., and K. A. Dunne (1994), Sensitivity of the global water cycle to the water-holding capacity of land, J. Clim., 7, 506-526.

Mironov, V., M. Dobson, V. Kaupp, S. Komarov, and V. Kleshchenko (2004), Generalized refractive mixing dielectric model for moist soils, IEEE Trans. Geosci. Remote Sens., 42, 773-785.

Nepstad, D. C., C. R. Carvalho, E. A. Davidson, P. H. Jipp, P. A. Lefebre, G. H. Negrelros, E. D. da Silva, S. E. Stone, T. A. Trumbore, and S. Vieira (1994), The role of deep roots in the hydrological and carbon cycles of Amazonian forests and pastures, Nature, 372, 666-669.

Njoku, E. G. (2004), Updated daily. AMSR-E/AQUA daily L3 surface soil moisture, interpretive parms, \& QC EASE-Grids, http://nsidc.org/data/ docs/daac/ae land3 13 soil moisture.gd.html, Snow and Ice Data Cent., Boulder, Colo.

Njoku, E. G., T. Jackson, V. Lakshmi, T. Chan, and S. Nghiem (2003), Soil moisture retrieval from AMSR-E, IEEE Trans. Geosci. Remote Sens., 41, $215-229$ 
Njoku, E. G., P. Ashcroft, T. K. Chan, and L. Li (2005), Global survey and statistics of radio-frequency interference in AMSR-E land observations, IEEE Trans. Geosci. Remote Sens., 43, 938-947.

Noilhan, J., and S. Planton (1989), A simple parameterization of land surface fluxes processes for meteorological models, Mon. Weather Rev., 117, $536-549$.

Pellarin, T., et al. (2003), Two-year global simulation of L-band brightness temperature over land, IEEE Trans. Geosci. Remote Sens., 41, 2135-2139.

Pellarin, T., H. Kerr, and J.-P. Wigneron (2006), Global simulation of brightness temperatures at 6.6 and $10.7 \mathrm{GHz}$ over land based on SMMR data set analysis, IEEE Trans. Geosci. Remote Sens., 44, 2492-2505.

Redelsperger, J.-L., C. Thorncroft, A. Diedhiou, T. Lebel, D. Parker, and J. Polcher (2006), African Monsoon Multidisciplinary Analysis (AMMA): An international research project and field campaign, Bull. Am. Meteorol. Soc., 87, 1739-1746.

Schmugge, T. (1992), A dielectric model of the vegetation effects on the microwave emission from soils, IEEE Trans. Geosci. Remote Sens., 30, $757-760$.

Taylor, C. (2008), Intraseasonal land-atmosphere coupling in the West African monsoon, J. Clim., 21, 6636-6648, doi:10.1175/2008JCLI2475.1.

Taylor, C., D. Parker, and P. Harris (2007), An observational case study of mesoscale atmospheric circulations induced by soil moisture, Geophys. Res. Lett., 34, L15801, doi:10.1029/2007GL030572.

Taylor, K. (2001), Summarizing multiple aspects of model performance in a single diagram, J. Geophys. Res., 106, 7183-7192.

Vall-llossera, M., M. Cardona, S. Blanch, A. Camps, A. Monerris, L. Corbella, F. Torres, and N. Duffo (2005), L-band dielectric properties of different soil types collected during the mouse 2004 field experiment, paper presented at IGARSS '05, Inst. of Electr. and Electron. Eng., Seoul.

van den Hurk, B., P. Viterbo, A. Beljaars, and A. Betts (2000), Offline validation of the ERA40 surface scheme, ECMWF Tech. Memo. 295, 43 pp., Eur. Cent. for Medium-Range Weather Forecasts, Reading, U. K.

Viterbo, P., and A. C. M. Beljaars (1995), An improved land surface parameterization scheme in the ECMWF model and its validation, ECMWF Tech. Memo. 75, 52 pp., Eur. Cent. for Medium-Range Weather Forecasts, Reading, U. K.
Wang, J. R., and T. Schmugge (1980), An empirical model for the complex dielectric permittivity of soils as a function of water content, IEEE Trans. Geosci. Remote Sens., 18, 288-295.

Wegmüller, U., C. Mätzler, and E. Njoku (1995), Canopy opacity models, in Passive Microwave Remote Sensing of Land-Atmosphere Interactions, edited by P. Pampaloni et al., pp. 375-387, VSP, Utrecht, Netherlands.

Wigneron, J.-P., A. Chanzy, J.-C. Calvet, and N. Bruguier (1995), A simple algorithm to retrieve soil moisture and vegetation biomass using passive microwave measurements over crop fields, Remote Sens. Environ., 51, $331-341$.

Wigneron, J.-P., J.-C. Calvet, and Y. H. Kerr (1996), Monitoring water interception by crop fields from passive microwave observations, Agric. For: Meteorol., 80, 177-194.

Wigneron, J.-P., et al. (2007), L-band Microwave Emission of the Biosphere (L-MEB) Model: Description and calibration against experimental data sets over crop fields, Remote Sens. Environ., 107, 639-655.

G. Balsamo, P. de Rosnay, and M. Drusch, European Centre for MediumRange Weather Forecasts, Shinfield Park, Reading RG2 9AX, UK. (Patricia.Rosnay@ecmwf.int)

A. Boone and B. Decharme, CNRM, Météo-France, 42 avenue Coriolis, F-31057 Toulouse CEDEX 1, France.

P. Harris, Centre for Ecology and Hydrology, Maclean Building, Crowmarsh Gifford, Wallingford OX10 8BB, UK.

Y. Kerr, Centre d'Etudes Spatiales de la Biosphère, 18 avenue Edouard Belin, BPI 2801, F-31401 Toulouse CEDEX 9, France.

T. Pellarin, Laboratoire d'étude des Transferts en Hydrologie et Environnement, BP 53, F-38041 Grenoble CEDEX 9, France.

J. Polcher, Laboratoire de Météorologie Dynamic, IPSL, Tour 45, 3eme étage, Case 99, 4 place Jussieu, F-75252 Paris CEDEX 5, France.

J.-P. Wigneron, Ecologie Fonctionnelle et Physique de l'environnement, INRA Centre Bordeaux-Aquitaine B.P. 81, F-33883 Villenave d'Ornon CEDEX, France. 